\title{
DELITOS DE ORGANIZACIÓN: LOS MODELOS DE “CONSPIRACY” Y "ASOCIACIÓN CRIMINAL" EN EL DERECHO INTERNO Y EN EL DERECHO INTERNACIONAL
}

\section{Nicolás Santiago Cordini*}

\begin{abstract}
Resumen: El Derecho penal del nuevo siglo experimenta un incremento de tipos penales basados en el elemento organización. La aparición de este fenómeno se da tanto en el Derecho interno como en el Derecho internacional. Uno de los factores que explican este fenómeno es el proceso de internalización del Derecho penal. El legislador nacional y los jueces nacionales no son más soberanos de la promulgación y de la aplicación de las leyes penales, si no están ligados a obligaciones internacionales. Este proceso de internacionalización no resulta posible sin la presencia de la tradición jurídica del Common Law. En este trabajo nos proponemos analizar los delitos de organización, a partir del estudio de los modelos de conspiracy y participación en una asociación criminal, y poner al descubierto cómo figuras delictivas creadas en función del sistema del Common Law acarrean disfuncionalidades si se las aplica a
\end{abstract}

Doctor en Derecho, Investigador y Profesor de Derecho penal I, Facultad de Ciencias Jurídicas y Sociales - Universidad Nacional del Litoral, Centro de Investigaciones de la FCıslunt, Cándido Pujato 2751, Santa Fe, Argentina. Correo-e: ncordini@fcjs.unl.edu.ar. Fecha de recepción: 6 de junio de 2017. Fecha de modificación: 15 de junio de 2017. Fecha de aceptación: 31 de agosto de 2017. Para citar el artículo: NiCOLÁs SANTIAGo CORDINI. "Delitos de organización: los modelos de 'conspiracy' y 'asociación criminal' en el Derecho interno y en el Derecho internacional”, en Revista Derecho Penal y Criminología , Vol. 38, n. ${ }^{\circ}$ 104, enero-junio de 2017, Bogotá, Universidad Externado de Colombia, pp. 75-120. DOI: https://doi.org/10.18601/ 01210483.v38n104.03 
nuestro sistema de imputación jurídico-penal, cuyo eje central lo constituye la teoría del delito.

Palabras clave: Internacionalización, Derecho penal, Conspiración, Asociación criminal, Disfuncionalidad

\title{
ORGANIZED CRIME: THE MODELS OF "CONSPIRACY" AND "CRIMINAL ASSOCIATION" IN DOMESTIC AND IN INTERNATIONAL LAW
}

\begin{abstract}
The Criminal Law of the new century experiences an increase of criminal offences based on the organized element. The emergence of this phenomenon happens in Domestic Law as well as in International Law. The national legislator and the national judges are not more sovereigns of the enactment and the enforcement of the Criminal law, but they are constrained by international legislation. In this process of internationalization, it is not possible to disregard the legal tradition of Common Law. In this paper, we endeavour to analyse the organized crime, based on the study of the models of "conspiracy" and "participation in a criminal association, and expose how criminal offences created in the system of Common Law lead to dysfunctionalities if they are applied in our system of criminal imputation, whose core is the "theory of crime".
\end{abstract}

Keywords: Internationalization, Criminal Law, Conspiracy, Criminal Association, Dysfunction.

\section{INTRODUCCIÓN}

La existencia de figuras delictivas que se configuran a través del actuar concertado de varias personas no conlleva ninguna novedad para el Derecho penal. Así, los clásicos delitos de pertenencia a una asociación criminal o bien la existencia de agravantes de delitos clásicos, como es el caso del hurto cuando es cometido en "banda", requirieron de argumentos, tanto de la doctrina como de la jurisprudencia, ya sea para fundamentar su constitucionalidad, en el primero de los casos, o bien para establecer la diferencia entre el grupo (banda) y la participación en sentido estricto, en el segundo caso. Lo que resulta novedoso para el Derecho penal clásico -si es posible seguir utilizando dicha categoría- es el incremento del elemento organización al interior de las legislaciones penales ${ }^{1}$. Este incremento es la resultante de varios fac-

1 Solo para citar un ejemplo: a lo largo de la última década del siglo xx, en la legislación penal alemana, más allá de los delitos en banda del StGB, fueron introducidas múltiples disposiciones que consagraron la comisión en banda, ya fuera como agravante o como tipo penal especial. Como aclara Romero 
tores, entre ellos, un proceso de aceleración social ${ }^{2}$, la aparición de nuevas formas de criminalidad $^{3}$, propias de la modernidad tardía (v.gr. delitos tales como el tráfico de estupefacientes o la trata de personas), el impacto en la legislación local del proceso de internalización del Derecho penal, etc., que pueden ser resumidos bajo el concepto, desarrollado por Silva Sánchez, expansión del Derecho penal ${ }^{4}$. En otros términos, las infracciones relacionadas con una asociación penalmente ilícita forman parte, de modo destacado, del marco político-criminal general de la expansión cuantitativa y cualitativa del sistema jurídico-penal ${ }^{5}$. En el presente trabajo nos proponemos analizar este fenómeno y poner al descubierto cómo figuras delictivas creadas a partir de otros sistemas de imputación jurídico-penal -básicamente el Common Law-trae como consecuencia disfuncionalidades si se los aplica a nuestro sistema de imputación jurídico-penal ${ }^{6}$, cuyo eje central lo constituye la teoría del delito.

Sánchez: "Llama la atención, no tanto el incremento de tipos penales cualificados por la comisión en banda, y con ello la extensión de los delitos principales, sino más bien que, para la configuración de esta agravación punitiva, no se recurrió más al requisito de "intervención de varios miembros de la banda en el delito concreto", sino que, por el contrario, se siguió el modelo introducido por la Ley de Tráfico de sustancias estupefacientes": Romero SÁnCHEZ, ANGÉLICA. La Asociación criminal y los delitos en banda en el Derecho penal alemán: Fundamentos históricos, dogmáticos y de política criminal. Bogotá: Universidad Externado de Colombia, 2015.

2 Según Rosa, las sociedades occidentales están en proceso de aceleración (Beschleunigung). Dicha aceleración tiene lugar en tres planos diferenciados, que en la mayoría de casos aparecen conjugados entre sí: a) la aceleración tecnológica (los procesos orientados al transporte, la comunicación y la producción que transforman el "régimen espacio-temporal" de la sociedad, acelerándola desde dentro); b) la aceleración del cambio social (una aceleración de la sociedad misma, esto es, de las instituciones que organizan el proceso de producción y reproducción, como son la familia o el sistema de empleo, las cuales se encuentran en una situación de progresivo declive en cuanto a estabilidad y perdurabilidad se refiere) y, por último, c) la aceleración del ritmo de vida (un incremento de episodios de acción o experiencia por unidad de tiempo) (HARTMut Rosa (2005). Beschleunigung. Die Veränderung der Zeitstruktur in der Moderne. Frankfurt am Main: Suhrkamp, 2005).

3 El actual cambio social en la sociedad del riesgo y de la información mundial, acarrea cambios en el desarrollo de la criminalidad, así como en el Derecho penal y la política criminal.

4 Véase: Jesús-MARÍA Silva SÁNCHEZ. La expansión del derecho penal. Aspectos de la política criminal en sociedades postindustriales, $2^{\text {a }}$ edición, Madrid, Civitas, 2001.

5 Manuel Cancio Meliá. "El injusto en los delitos de organización”: peligro y significado" en MAnuel Cancio Melía, Jesús-María Silva Sánchez, Delitos de organización, Buenos Aires, B de F, 2008 , p. 27.

6 La teoría de la imputación, en términos generales, responde a la problemática de cuándo y bajo qué condiciones se puede establecer una relación, penalmente relevante, entre una persona y un suceso de manera que a esa persona se la pueda considerar autor y reprocharle el hecho mediante la aplicación de una pena. Véase, JoAchim HruschKa (1976). Strukturen der Zurechnung, Berlin, Walter de Gruyter, 1976, p. 13 y ss. En igual sentido: WILFRIED HASSEMER “Person, Welt und Verantwortlichkeit Prolegomena einer Lehre von der Zurechnung im Strafrecht” en KLAUs LÜDERSSEN (comp.), Aufgeklärte Kriminalpolitik oder Kampf gegen das Böse?, Nomos: Baden-Baden, Tomo I, 1998, p. 350. 


\section{LA INTERNACIONALIZACIÓN DEL DERECHO PENAL}

El Derecho penal clásico es producto de ordenamientos jurídicos nacionales, unitarios y cerrados. El Derecho penal de la globalización económica y de la integración supranacional es, en cambio, un Derecho crecientemente unificado, pero, al mismo tiempo, menos garantista, en el que se flexibilizan las reglas de imputación y en el que se relativizan las garantías político-criminales sustantivas y procesales ${ }^{7}$. Las notas distintivas de este nuevo modelo de Derecho penal son las siguientes:

1. La internacionalización del Derecho penal se realiza a partir de instrumentos de Derecho internacional ${ }^{8}$. En un primer momento, se desarrolló a partir del Derecho internacional consuetudinario, principios que fueron posteriormente codificados en el Estatuto de Roma, que creó la Corte Penal Internacional. Aunque son, principalmente, los tratados bi y multilaterales los que realizan el mencionado proceso de internacionalización. Estos convenios afectan a gran número de delitos tales como el terrorismo, el tráfico de armas y de drogas, la trata de personas, la prostitución y la pornografía infantil, la criminalidad organizada, el lavado de dinero, etc.

A veces los términos "crimen internacional" y "crimen transnacional" son usados de manera indistinta para describir una conducta delictiva que ha tenido dimensiones internacionales ${ }^{9}$. Bajo la óptica del Derecho internacional existe, sin embargo, una

7 Jesús-María Silva SÁnchez. La expansión del derecho penal. Aspectos de la política criminal en sociedades postindustriales, $2^{\text {a }}$ edición, Madrid, Civitas, 2001, p. 81.

8 Siguiendo a Triffterer: "derecho penal internacional en sentido formal es el conjunto de todas las normas de naturaleza penal del derecho internacional, que conectan a una conducta determinada - crímenes internacionales - ciertas consecuencias típicamente reservadas al derecho penal y que, como tales, son aplicables directamente". ОтTO TRIFFTERER. Dogmatische Untersuchungen zur Entwicklung des materiellen Völkerstrafrechts seit Nürnberg, Freiburg i. Br., Albert, 1966, p. 34. Para Ambos, se trata de una combinación de principios de Derecho penal y de Derecho internacional. Del primero toma las ideas de responsabilidad individual y de reprochabilidad de una determinada conducta, del segundo; en cambio, toma las figuras penales, sometiendo a la conducta en cuestión a una punibilidad autónoma de Derecho internacional (principio de responsabilidad penal directa del individuo según el Derecho internacional). KaI Ambos. Internationales Strafrecht. Strafanwendungsrecht - Völlkerstrafrecht - Europäisches Strafrecht - Rechthilfe, $4^{\mathrm{a}}$ edición, München, C. H. Beck, 2014,pp. 100-101.

9 Esta problemática se da principalmente en la lengua inglesa, en la que ambas categorías son agrupadas bajo el concepto International Criminal Law. En lenguas romances como el español o el francés se puede distinguir entre Derecho penal internacional (Droit pénal International) y Derecho Internacional penal (Droit International énal). Cassese sostiene que los juristas comunes utilizan el concepto International Criminal Law, que incluye normas internacionales dirigidas a proscribir ciertas categorías de conductas (crímenes de guerra, crímenes contra la humanidad, genocidio, etc.) y aquellas que posibilitan hacer responsables a aquellas personas que participan de dichas conductas. Antonio CASSESE. International Criminal Law, $2^{a}$ edición, Oxford, Oxford University Press, 2007, p. 3. Esta definición se aproxima con el concepto "Derecho internacional Penal" en español o "Droit international pénal” en francés. AnNE-LAure VAurs Chaumette. Les sujets du droit international pénal. Vers une nouvelle définition de la personnalité juridique internationale?, Paris, Pedone, 2009, 
diferencia entre estos actos. Se trata, principalmente, de la naturaleza del delito en cuestión. Los crímenes internacionales conciernen a la comunidad internacional como un todo, o delicta juris gentium. Son conductas que amenazan el orden internacional o la comunidad internacional. Estos delitos están directamente prohibidos por el Derecho internacional, a saber, por el "Derecho penal internacional" (Derecho internacional penal en la nomenclatura hispana), y establecen una responsabilidad criminal individual. Actualmente, el número de delitos que pertenecen a esta categoría es limitado y están codificados en el Estatuto de Roma, que creó la Corte Penal Internacional. La prohibición de estos delitos está firmemente contemplada como costumbre internacional, y constituyen ius cogens ${ }^{10}$. Estos delitos, a diferencia de los delitos transnacionales, pueden ser cometidos en la jurisdicción de un solo Estado ${ }^{11}$.

El crimen transnacional, por el contrario, no es generalmente considerado un delito concerniente a la comunidad internacional. Puede afectar intereses de más de un Estado, pero no todos los Estados que colectivamente constituyen la comunidad internacional ${ }^{12}$. En otras palabras, el crimen transnacional no es visto como tan grave como el crimen internacional. Los delitos pertenecientes a esta categoría (especialmente los delitos relacionados con el crimen organizado: tráfico de estupefacientes, trata de personas, lavado de activos, etc.) versan sobre una emergente rama del Derecho internacional conocida como Derecho penal transnacional (Derecho penal internacional en la nomenclatura hispana), que no establece responsabilidad penal individual en el Derecho internacional, no prohíbe conductas directamente. En su lugar, promueve prevención, persecución y sanción de un delito a través del Derecho penal interno, mediante la imposición a los Estados de promulgar legislación al respecto $^{13}$. Además, la prohibición del crimen organizado no es generalmente con-

p. 18. En el mismo Sentido, KAI AмBos. Internationales Strafrecht. Strafanwendungsrecht - Völlkerstrafrecht-Europäisches Strafrecht - Rechthilfe, 4ª edición, München, C. H. Beck, 2014, pp. 1-2.

10 Ian Brownlie. Principles of Public International Law, $6^{\text {th }}$ ed., Oxford, Oxford University Press, 2003, p. 6.

11 Том Овоката. Transnational Organised Crime in International Law, Oxford, Hart Publishing, p. 30 .

12 Antonio CASSESE. International Criminal Law, 2a edición, Oxford, Oxford University Press, 2007, p. 12 .

13 El propósito principal del Derecho Penal Transnacional es promover (indirectamente) la prevención de delitos a nivel nacional. Así, la Convención de Naciones Unidas contra la Delincuencia Organizada Transnacional y sus Protocolos obligan a los Estados a criminalizar varias conductas relacionadas con el crimen organizado. Existen otras convenciones represivas preexistentes que obligan a los Estados a prohibir determinados delitos incluyendo el tráfico de drogas (Convención de Naciones Unidas contra el Tráfico Ilícito de Estupefacientes y Sustancias Psicotrópicas, Viena, 1988), la propiedad cultural (Convención sobre las Medidas que Deben Adoptarse para Prohibir e Impedir la Importación, la Exportación y la Transferencia de Propiedad Ilícita de Bienes Culturales, UNESCO, París, 1970), especies en peligro (Convención sobre el Comercio Internacional de Especies Amenazadas de Fauna y Flora Silvestres), material nuclear (Convención Protección Física de los Materiales Nucleares, 1979), delitos relacionados con la pornografía infantil (Protocolo Facultativo de la Convención de los Derechos del Niño relativo a la venta de niños, la prostitución infantil y la utilización de los niños 
siderada como parte de la costumbre internacional ${ }^{14}$. En suma, los crímenes transnacionales organizados pueden apropiadamente ser definidos como mala pohibita pero no, en general, como regla mala in $\mathrm{se}^{15}$, o sea conductas que son malas porque están prohibidas por la ley ${ }^{16}$.

El proceso de internacionalización del Derecho penal al que hacemos referencia se desarrolla, fundamentalmente, a través del Derecho penal transnacional o también llamado Derecho penal internacional, a partir de la incorporación en las legislaciones nacionales de tipos penales surgidos de convenciones internacionales (treaty crimes).

2. El Derecho penal resultante del proceso de internacionalización es un Derecho orientado a dar respuesta a demandas fundamentalmente prácticas. El estilo de argumentación utilizado es más bien pragmático y, en primera línea, orientado a argumentos fácticos ${ }^{17}$. El pragmatismo que caracteriza a este modelo se visualiza en que los actores -fundamentalmente los Estados- no discuten acerca de la creación de un nuevo Derecho penal basado en la redefinición de sus principios, sino que, ante una determinada problemática, por ejemplo, el narcotráfico o la criminalidad organizada, la respuesta es punitiva, plasmada en una convención internacional. En este proceso de codificación de los llamados treaty crimes han retrocedido las discusiones dogmáticas, categoriales o sistemáticas ${ }^{18}$. La exigencia de dar respuesta a la delincuencia de la globalización se concibe, en general, en términos punitivistas. A partir de acuerdos internacionales se intenta armonizar las legislaciones penales

en la pornografía) cibercrimen (Convenio sobre Cibercriminalidad), falsificación de moneda (Convenio Internacional para la Represión de la Falsificación de Moneda, Ginebra, 1929). Sin embargo, la Convención de Palermo un objeto de prohibición específico como en las anteriores mencionadas, su beneficio yace en que puede ser usada para perseguir y punir una variedad de actividades criminales, en la medida que ellos sean delitos graves cometidos por un grupo transnacional, como es definido en la misma convención.

14 Sin embargo, esta cuestión puede ser puesta en entre dicho, porque el crimen organizado ha existido por largo tiempo en la historia, y los Estados han criminalizado variadas formas de conductas asociativas en sus legislaciones locales. Inclusive, se ha argumentado que el tráfico de personas puede ser visto como un crimen contra la humanidad en determinadas circunstancias. TOM OBAKATA. "Trafficking of Human Beings as a Crime Against Humanity: Some Implications for the International Legal System" en International and Comparative Law Quarterly, vol. 54, 2005, p. 445.

15 William Shabas. "International Crime", en David Amstrong (ed.) Routledge Handbook of International Law, London, Routledge-Cavendish, 2008, p. 269.

16 Том Овоката. Transnational Organised Crime in International Law, Oxford, Hart Publishing, 2010, p. 31 .

17 WAlter Perron. "Europäische und transnationale Strafrechtspflege als Herausforderung für eine moderne Strafrechtdogmatik“, en KLAus TiEDEMman et al. (eds.) Die Verfassung moderner Strafrechtspflege. Erinnerung an Joachim Vogel, Nomos, Baden-Baden, 2016, p. 316.

18 KаI Амвоs. "Zur Zukunft der deutschen Strafrechtswissenschaft: Offenheit und diskursive Methodik statt selbstbewusster Provinzialität“, en Klaus Tiedemman et al. (eds.) Die Verfassung moderner Strafrechtspflege. Erinnerung an Joachim Vogel, Nomos, Baden-Baden, 2016, p. 324. 
en aras de evitar que determinadas conductas permanezcan impunes en algunos territorios ("paraísos jurídico-penales”).

3. El legislador nacional y los jueces nacionales no son más, desde hace tiempo, soberanos de la promulgación y de la aplicación de las leyes penales, sino que están extensamente ligados a obligaciones internacionales ${ }^{19}$. Siguiendo a Vogel,

La internacionalización del Derecho penal y del proceso penal es una forma de aparición de la interlegalidad ${ }^{20}$. Los sistemas jurídicos inter y supranacionales influyen en los ordenamientos jurídico penales nacionales y provocan su resistencia (...) El hecho de que la criminalidad actúe, a causa de la globalización, de forma cada vez más transnacional, como en el caso del terrorismo internacional, la criminalidad organizada internacional o el tráfico ilegal de drogas o de personas, hace de motor de la internacionalización ${ }^{21}$.

4. Ante la necesidad de dar una respuesta (punitiva) a la delincuencia transnacional no resulta posible que el Derecho penal de base germánica prescinda de la tradición jurídico-penal anglosajona (Common Law). Se percibe, en los últimos años, una pérdida ininterrumpida de significado internacional de la ciencia jurídico-penal alemana en todos los niveles. A pesar de que ella todavía conserva, de todas formas, influencia en numerosos Estados llamado sistema del Civil Law ${ }^{22}$. Sin embargo, los conceptos básicos de la dogmática jurídico-penal alemana tales como bien jurídico o la división entre injusto y culpabilidad no son tenidos en cuenta en el patrimonio penal común internacional o europeo ${ }^{23}$. ¡Cuánto ha invertido la dogmática jurídico-

19 Walter Perron. "Europäische und transnationale Strafrechtspflege als Herausforderung für eine moderne Strafrechtdogmatik“, en KLAus Tiedemman et al. (eds.) Die Verfassung moderner Strafrechtspflege. Erinnerung an Joachim Vogel, Nomos, Baden-Baden, 2016, p. 319.

20 Según De Sousa Santos, "La interlegalidad es la dimensión fenomenológica del pluralismo jurídico. Se trata de un proceso altamente dinámico porque los diferentes espacios jurídicos no son sincrónicos y por eso también las mezclas de códigos de escala, de proyección o de simbolización son siempre desiguales e inestables. La mezcla de códigos es visible en todos los procesos sociales (...) Es también visible en el modo como el derecho global emergente (...) se apropia de los lenguajes jurídicos, locales o tradicionales". BoAventura De Sousa SANTOS. Crítica de la razón indolente: contra el desperdicio de la experiencia: para un nuevo sentido común: la ciencia, el derecho y la política en la transición paradigmática, Bilbao, Desclée de Brouwer, 2003, p. 251.

21 JoAchim Vogel. "La internacionalización del Derecho penal y del Proceso penal”, en: Revista penal, vol. 22, 2008, p. 161. En igual sentido, JOACHIM VoGEL (2002). "Europäische Kriminalpolitik europäische Strafrechtsdogmatik” en: Goltdammer's Archiv für Strafrecht, 2002, p. 520.

22 Kai Ambos. "Zur Zukunft der deutschen Strafrechtswissenschaft: Offenheit und diskursive Methodik statt selbstbewusster Provinzialität“ en Klaus Tiedemman, et al. (eds.) Die Verfassung moderner Strafrechtspflege. Erinnerung an Joachim Vogel, Nomos, Baden-Baden, 2016, 2016, p. 322.

23 JOACHIM VOGEL. "Strafrecht und Strafwissenschaft im internationales und europäisches Rechtsraum" en Juristen Zeitung, 2012, p. 25. En el ámbito de la teoría general o parte general del Derecho penal es, en gran parte, ignorado el concepto de delito deductivamente aplicado y colocado a un alto nivel de abstracción con sus propias formas (el concepto final de acción con la consecuente división 
penal alemana en el intento de zanjar la división entre injusto (Unrecht) y culpabilidad (Schuld)! Algo que en otros sistemas jurídicos resulta, aún hoy, totalmente desconocido. El "encuentro de culturas jurídicas" resulta confuso, la receptación de conceptos y categorías teóricas provenientes de otras tradiciones jurídicas es, muchas veces, ignorado por el legislador; es la dogmática jurídico-penal la que, en una suerte de defensa de trinchera, denuncia la proliferación de este fenómeno. Ante esta situación, una de las pocas conclusiones que pueden extraerse es que el intento de universalizar la dogmática jurídico-penal alemana resulta una quimera ${ }^{24}$. Ya a inicios del nuevo milenio Roxin anunciaba que "La ciencia del derecho penal deberá fortalecer los fundamentos penales para un derecho penal supranacional, esto es en un tiempo previsible: el Derecho penal europeo y un Derecho penal internacional" 25 . Sin embargo, la ciencia jurídico-penal alemana, salvo raras excepciones ${ }^{26}$, no ha tenido influencia en el desarrollo de la legislación penal internacional ${ }^{27}$.

entre un dolo psicológico y una culpabilidad normativa, la diferencia entre causas de justificación y de exculpación así como el legitimado penalmente concepto de bien jurídico protegido). El único resultado convincente de la teoría penal alemana es la teoría del dominio del hecho desarrollada por Claus Roxin. La misma ha sido, reconocida, no solo en los por otros sistemas de imputación, sino también por tribunales penales internacionales. Kai AмBos. "Zur Zukunft der deutschen Strafrechtswissenschaft: Offenheit und diskursive Methodik statt selbstbewusster Provinzialität" en KLAus Tiedemman et al. (eds.) Die Verfassung moderner Strafrechtspflege. Erinnerung an Joachim Vogel, Nomos, Baden-Baden, 2016, p. 323. Acertadamente Satzger sostiene que la complejidad de ninguna manera representa un déficit de una ciencia, sino precisamente si no es signo de una muy desarrollada dogmática; como en el ámbito del Derecho penal alemán sin un alto nivel de abstracción y complejidad, es evidente de inmediato, que no pueden entenderse, en el primer intento, figuras y frases. Helmut StaZger. "Die Rolle einer modernen deutschen Strafrechtswissenschaft im europäischen und internationalen Kontext", en Klaus Tiedemman et al. (eds.) Die Verfassung moderner Strafrechtspflege. Erinnerung an Joachim Vogel, Nomos, Baden-Baden, 2016, p. 280.

24 Véase: Hans Welzel. Vom Bleibenden und vom Vergänglichen in der Strafrechtswissenschaft, Marburg a. d. Lahn, Elwert, pp. 16-17. Armin KAUfMAnN (1985). "Das Übernationale und Überpositive in der Strafrechtswissenschaft” en HANS-HEINRICH JESCHECK et al. (eds). Gedächtnisschrift für Zong Uk Tjong, Seibundo, Tokio, 1964, pp. 100-111.

25 Claus Roxin. "Die Strafrechtswissenschaft von den Angaben der Zukunft" en Albin Esser, et al. (eds). Die deutsche Strafrechtswissenschaft vor der Jahrtausendwende. Rückbesinnung und Ausblick, München, Beck, 2000, p. 369.

26 Así en la Conferencia de Kampala (Uganda) en el año 2010, Alemania jugó un papel decisivo en la Revisión del Estatuto de Roma, especialmente en la configuración del delito de "agresión".

27 Si la legislación penal alemana actual puede ser contemplada como internacional y europea, en especial como modélica y de mucha influencia, puede, con todo derecho, ser puesta en duda. El código penal alemán en su configuración esencial actual data de las reformas penales de los años 1960 y 1970 y no puede valer más como modelo a seguir. En los escenarios de política criminal europeos e internacional Alemania no es ningún actor preponderante, las iniciativas decisivas, o sea las decisiones son llevadas adelante por otros Estados. JOACHIM VOGEL. "Strafrecht und Strafwissenschaft im internationales und europäisches Rechtsraum“ en Juristen Zeitung, 2012, 2012, pp. 25-26. Asimismo de manera escéptica respecto del rol actual de la dogmática jurídico-penal alemana se manifiesta Silva Sánchez; al respecto sostiene "Debo confesar que abrigo el temor de que, para la dogmática, 'cualquier tiempo pasado fue mejor'. En efecto, los grandes maestros alemanes se han jubilado o están a punto de hacerlo, y buena parte de sus sucesores -en todo caso, algunos de los más influyentes y brillantes- parecen más dispuestos a adorar al becerro de oro de Bruselas (o quizá de Washington) 


\section{DERECHO PENAL INTERNACIONAL Y DELITOS DE ORGANIZACIÓN}

A pesar del consenso que el crimen organizado representa un problema de orden mundial, no existe acuerdo acerca de lo que el crimen organizado realmente es ${ }^{28}$. El actual debate sobre cómo debería ser definido el concepto en cuestión, con el foco puesto sobre los individuos y las estructuras de la organización o si, por el contrario, debería ser definido con base en las actividades criminales y como estas se encuentran organizadas, mantiene tanto a científicos sociales como a los juristas en un círculo vicioso $^{29}$. Entre las diversas disciplinas que abordan este fenómeno, la criminología, la sociología, la economía, las relaciones internacionales, etc., existen conceptos vagos acerca del objeto de estudio ${ }^{30}$, y el consenso al que se ha llegado en el ámbito

que a seguir a sus predecesores. O tempora, o mores!”. JESÚs-MARÍA SiLVA SÁnCHEz. "Prólogo 2012. El sistema moderno del derecho penal: cuestiones fundamentales" en BERD SCHINEMANN (comp.) El sistema moderno del derecho penal. Cuestiones fundamentales. Estudios en honor del Claus Roxin en su $50^{\circ}$ aniversario, $2^{\mathrm{a}}$ edición, Buenos Aires, B de F, 2012, pp. XV-XVI.

28 Siguiendo a Lampe, es importante comprender por qué es tan difícil arribar a un concepto de crimen organizado y por qué, aún hoy, hay gran confusión. Contrariamente a lo que uno puede esperar, esto no tiene que ver tanto con las siniestras y clandestinas formas de los gangsters y mafiosos. En cambio, tiene que ver con un problema general de como las personas perciben y dan sentido al mundo en el que viven. En primer lugar, a las personas no les es posible comprender la realidad en toda su complejidad. Su percepción es inevitablemente selectiva, lo que significa que focalizan en ciertos aspectos mientras descartan otros. En segundo lugar, lo que ven intentan enmarcarlo en categorías que están en consonancia con sus puntos de vista preexistentes, actitudes y valores. En tercer lugar, las personas dan sentido al mundo no como individuos sino como seres sociales. Llegan a compartir comprensiones de como ver e interpretar la realidad en un proceso que ha sido llamado "construcción social de la realidad". Es importante destacar que la construcción social de la realidad es un proceso dinámico, influenciado por diversos factores, con varias posibles consecuencias. Esto también es aplicable a la noción de crimen organizado. El crimen organizado no es algo que exista de manera claramente discernible fuera del mundo real, tal como las pirámides de Egipto. Esto no significa que él sea un producto de la imaginación sin ninguna relación con la realidad. Los diversos fenómenos que valiosamente etiquetados como crimen organizado son bastante real -a pesar de algunas exageraciones, incomprensiones y mistificaciones. Sin embargo, para poder hablar de crimen organizado, algunos aspectos del universo social deben, primeramente, ser separados de la densa red de individuos, acciones y estructuras e incorporadas en un contexto unificador en el nivel conceptual. En este caso, es un constructo, un intento de dar sentido a una compleja realidad social. Hablando estrictamente, el crimen organizado como algo inequívoco y autoevidente solo existe en el papel, en la combinación de dos palabras: "crimen" y "organizado". Al mismo tiempo, el significado de ambas palabras es flácido, flexible y contradictorio. Por ejemplo, algunos asocian crimen organizado esencialmente con la organización criminal, mientras para otros el término crimen organizado refiere, principalmente, a la organización de los criminales. KLAUS von LAMPE. Organized Crime: Analyzing Illegal Activities, Criminal Structures, and Extra-Legal Governance, Los Angeles, Sage, 2016, p. 11-12.

29 Almir Maljevic. "Participation in a Criminal Organization” and "Conspiracy”. Different Legal Model Against Criminal Collectives, Duncker \& Humblot, Berlin, 2011, pp. 2-3.

30 Al investigar en materia de "crimen organizado", no contamos con un concepto, en tanto objeto de estudio, como punto de inicio. Por el contrario, el verdadero propósito del estudio sobre el "crimen organizado" o, para ser más preciso, utilizando el léxico jurídico-penal, "delitos de organización”, es determinar en qué consiste el mencionado fenómeno. Una definición de "delito de organización" es, por lo tanto, un posible resultado antes que una condición previa del estudio sobre la criminalidad organizada. KLAUS VON. "The study of organised crime: An assessment of the state of affairs" en Or- 
jurídico, a través de una convención internacional, no ha logrado, aún hoy, que los diversos Estados sigan operando con conceptos diversos ${ }^{31}$.

El sistema penal de EE.UU. es un Derecho local que se extiende globalmente, influyendo en los instrumentos internacionales, particularmente a partir de su posición dominante en las convenciones, produciendo, de esta manera, modificaciones en los ordenamientos jurídicos locales. Así, ideas tales como el Derecho penal de la empresa (corporate liability), los tipos penales relacionados con el crimen organizado, tales

ganised Crime: Norms, markets, regulation and research, Oslo, Unipub, 2009, p. 166. Lampe señala tres grandes problemas a la hora de conceptualizar el crimen organizado. En primer lugar, resulta difícil delinear la criminalidad organizada como un objeto de estudio; pues esta no es ni un claro fenómeno empírico discernible, ni encontramos acuerdo sobre cuál debe ser su "esencia" o "naturaleza". Más bien, una amplia variedad de personas, estructuras y eventos están, en variado grado y combinación, subsumidos en este concepto. Debido a este carácter esquivo, la frase "crimen organizado" puede asumir una experiencia de sí misma bastante independiente de la realidad social a la que se supone que debe estar relacionada. Es por ello que los investigadores en la materia no solo se enfrentan al desafío de establecer un concepto unívoco, sino que también tienen que lidiar con la dualidad del crimen organizado como una faceta de la realidad social y como una construcción social. La segunda dificultad está relacionada con la falta de una terminología precisa. Así, por ejemplo, conceptos básicos como los de "crimen organizado" y "redes criminales" son usados a veces indistintamente y en otras oportunidades son tratados como categorías analíticas diversas, creando, en consecuencia, mayores confusiones. El tercer problema surge cuando las visiones comúnmente sostenidas sobre la realidad del crimen organizado están en contradicción con las investigaciones científicas. Bastante a menudo lo que es considerado por los medios masivos de comunicación, por los políticos o por los agentes aplicadores de normas como un hecho establecido (organización criminal), bajo un examen más próximo resulta ser un concepto erróneo; por lo tanto, los investigadores, no infrecuentemente, están en desacuerdo con estos formadores de opinión. KLAUS vON LAMPE. "Organised Crime Research in Perspective" en: Upperworld and Underworld in Cross-Border Crime, Nijmegen: Wolrd Legal Publishers, 2002, p. 191.

31 En el caso de Alemania, con la ley de lucha contra el tráfico ilegal de estupefacientes y otras formas de participación de la criminalidad organizada (OrgKG) del año 1992, fueron introducidas en la Ley Procesal Penal (StPO), medidas especiales de investigación y con ella fue prevista, con base constitucional, la persecución penal de la criminalidad organizada. El Derecho penal material, por el contrario, ha variado poco; hasta hoy no existe un tipo penal de criminalidad organizada (Organisierte Kriminalität-Straftatbestand). La criminalidad organizada debería, en adelante, ser comprendida bajo los tradicionales tipos de banda (Bande) y asociación criminal (kriminelle Vereinigung). ARNDT SINN (2016). Organisierte Kriminalität 3.0, Heidelberg, Springer, p. 4. En el caso de Inglaterra y Gales no existe ninguna legislación que provea una definición de crimen organizado. A la hora de imputar cargos, se recurre al clásico delito de conspiracy. Los Servicios Nacionales de Inteligencia Criminal han adoptado, a los fines laborales, una definición de crimen organizado o grupos como "aquellos involucrados, normalmente trabajando con otros, en continuas actividades delictivas graves, establecidos, ya sea, en el Reino Unido o bien, en cualquier otro lugar". Si bien este concepto no está en sintonía con el de "grupo delictivo organizado" de la UNTOC, el gobierno británico considera que el concepto referido captura en, en su esencia, aquello que constituye el crimen organizado. Tom Овоката. Transnational Organised Crime in International Law, Oxford: Hart Publishing, 2010, p. 157. En el caso de los EE.UU. existe la llamada RICO (Racketeer Influenced and Corrupt Organizations) Act, es una ley federal pensada para combatir el crimen organizado -especialmente de tipo mafioso- que prevé sanciones penales por los actos realizados por una organización criminal. Fue aprobada en 1970 durante la administración Nixon y, por lo tanto, es anterior al concepto adoptado por la ONU. 
como la trata de personas, el blanqueo de capitales o el tráfico de estupefacientes, o el propio concepto de "grupo delictivo oranizado" fueron originalmente conceptualizados por el Derecho penal de los EE.UU. ${ }^{32}$

En referencia a la criminalidad organizada, no debe perderse de vista el rol dominante que tuvo la política criminal de EEUU en materia de lucha contra el narcotráfico desde los años 1960 en la legislación internacional. ${ }^{33}$ Hubo una "americanización” de la respuesta de la comunidad internacional a problemática del narcotráfico, construida a partir del marco teórico establecido en las Convenciones de Naciones Unidas ${ }^{34}$. Estas convenciones fueron establecidas como resultado de una intensa y continua presión de los EE.UU. para liderar la política criminal en la materia. La Convención de Viena de 1988 Contra el Tráfico Ilícito de Estupefacientes y Sustancias Sicotrópicas está en línea con los objetivos de la diplomacia americana como se indica en las recomendaciones "Foreign Assistance" de la Reagan Organized Crime Comisssion ${ }^{35-36}$. Al mismo tiempo que la política criminal contra las drogas mostraba signos de ineficacia para combatir el flagelo, se estableció en la agenda internacional la necesidad de combatir un fenómeno más amplio, el propio de las organizaciones criminales. En la década del noventa el concepto "crimen organizado transnacional" emergió como un nuevo concepto en la academia y en el discurso popular. Esta categoría teórica surgió en una coyuntura histórica específica, cuando confluyeron factores sobresalientes, entre los cuales el más importante fue el fin de la guerra fría y su reemplazo por un nuevo orden mundial, que dio lugar a un nuevo discurso en

32 JoACHim Vogel. "Europäische Kriminalpolitik - europäische Strafrechtsdogmatik" en Goltdammer's Archiv für Strafrecht, 2002, p. 521.

33 Ethan Nadelmann. Cops Across Borders: The Internationalization of U.s. Criminal Law Enforcement, Pennsylvania, State University Press, 1993, p. 466.

34 En el ámbito de la ONU se han sucedido tres grandes Convenciones en la materia, a saber: a) la Convención Única de 1961 sobre Estupefacientes, b) el Convenio sobre Sustancias Sicotrópicas de 1971 y c) la Convención de Viena de 1988 Contra el Tráfico Ilícito de Estupefacientes y Sustancias Sicotrópicas.

35 Mike Woodiwiss. "Transnational organised crime: the global reach of an American concept" en A. EDWARDs, P. Gill (eds.), Transnational Organised Crime. Perspectives on global security. London, Routledge, 2003, p. 19.

36 Cabe destacar que, si bien la Convención de 1988 entiende al tráfico de estupefacientes y sustancias sicotrópicas como una modalidad del crimen organizado transnacional, no conceptualiza a la organización. Solamente en su artículo 3 establece que "1. Cada una de las partes adoptará medidas que sean necesarias para tipificar como delitos penales en su derecho interno, cuando se comentan intencionalmente: ... c) A reserva de sus principios constitucionales y de los conceptos fundamentales de su ordenamiento jurídico: ... iv) la participación en la comisión de alguno de los delitos tipificados en el presente artículo, la asociación y la confabulación para cometerlos..." y luego en el punto 5.5. del mismo artículo añade que "Las Partes dispondrán lo necesario para que sus tribunales y demás autoridades jurisdiccionales competentes puedan tener en cuenta las circunstancias de hecho que den particular gravedad a la comisión de los delitos tipificados de conformidad con el párrafo 1, del presente artículo, tales como: a) La participación en el delito de un grupo delictivo organizado del que el delincuente forme parte; b) La participación del delincuente en otras actividades delictivas internacionales organizadas". 
materia de seguridad predicando el "combate contra el crimen organizado". A partir del último decenio del siglo xx, diversos actores (políticos de diversos países, organizaciones internacionales, sector académico, etc.) fueron delineando el concepto "organización criminal transnacional" que tendrá su corolario en la Convención de Naciones Unidas contra la Delincuencia Organizada Transnacional y sus Protocolos (UNTOC) (Palermo, 2000).

De especial interés resultan las Convenciones de Viena de 1988 y la de Palermo de 2000, pues en ellas aparecen los delitos de organización ${ }^{37}$, tanto en la forma de conspiracy (conspiración o confabulación) como de "participación en una asociación criminal" ("grupo delictivo organizado"). En el rumbo de la lucha contra las organizaciones criminales en el Derecho internacional, y con la finalidad de armonizar las legislaciones nacionales dirigidas a dichos colectivos, elementos los dos modelos tradicionales ("participación en una organización criminal" y "conspiracy") han sido introducidos en instrumentos jurídicos internacionales. Se asume frecuentemente que los modelos internacionales combinan elementos de los modelos tradicionales y, de este modo, cumplen con los mínimos requerimientos para la criminalización de la participación en una organización criminal y la conspiracy en todos los países que todavía no han introducido tal o similares provisiones. Desde que los modelos internacionales desarrollados en la ONU son un tanto diversos de los modelos tradicionales, ${ }^{38}$ presentes en el Derecho interno, requieren ser analizados.

Con frecuencia, conspiracy y "participación en una asociación criminal" son tratados como equivalentes, aunque, luego de un análisis detallado, veremos que, si bien comparten un determinado objetivo o finalidad, difieren en su contenido y alcance, por lo que no pueden ser vistos como modelos sustitutivos. Antes de analizar los modelos en el Derecho internacional, presentaremos cómo se configuran estas figuras delictivas en el Derecho interno de los sistemas del Common Law y del Civil Law, respectivamente.

37 La categoría "organización" aparece al interior de las legislaciones nacionales a partir de las manifestaciones siguientes: a) la tipificación de delitos que serían característicos de tal forma de criminalidad (p. ej. el delito de lavado de activos, el delito de trata de personas, el tráfico de armas, etc.); b) la introducción del elemento agravante de organización en una serie de delitos más o menos tradicionales (p. ej. el caso del delito de robo calificado cuando es cometido "en banda"); c) los clásicos delitos de pertenencia a una organización como es el caso del delito de asociación criminal. En este caso el injusto sistémico de la asociación criminal (el ser miembro de la misma) es un injusto autónomo, independiente de los delitos concretos (delitos fin) que se puedan cometer a través de ella. A partir de esta clasificación, el componente organizacional aparece en la legislación penal a través de dos vías diversas: i) mediante el agravamiento del ilícito (Unrecht) y, por ende, de la pena en diversos delitos cuando el mismo se haya cometido a través de un grupo organizado (casos a y b) o bien, ii) mediante los delitos de mera pertenencia a una asociación criminal (caso c).

38 Almir Maljevic. "Participation in a Criminal Organization” and "Conspiracy”. Different Legal Model Against Criminal Collectives, Duncker \& Humblot, Berlin, 2011, pp. 21-22. 


\section{La conspiracy: el modelo del Common Law}

La conspiracy es el delito de organización característico del Common Law. Entre los diversos sistemas jurídicos que lo componen existen variantes de esta figura. En el presente trabajo la describiremos de modo genérico, aunque, al mismo tiempo, serán tratadas algunas particularidades de los sistemas de EE.UU. y de Inglaterra y Gales, respectivamente.

Esta figura delictiva puede ser definida como un acuerdo entre dos o más personas para cometer un delito, y a veces, más ampliamente, como un acuerdo cometer cualquier acto ilícito. Frecuentemente se dice que lo esencial del delito yace en el mero acuerdo y, con su solo perfeccionamiento el hecho es punible. Una definición más estrecha del delito exige un acto manifiesto en cumplimiento del acuerdo (overt act $)^{39}$.

El colectivo criminal en el modelo de conspiracy está constituido al menos por dos personas no exentas (non-exempted) que alcanzan el acuerdo para cometer un delito. Considerando el hecho que el delito de conspiracy en sí mismo está basado en un acuerdo, es comprensible que el mínimo número de personas suficientes y requeridas para los cargos de conspiracy sea de $\operatorname{dos}^{40}$. Despierta especial interés en esta figura delictiva tanto el objeto del acuerdo, el momento en que queda perfeccionado el delito, como el alcance de los efectos. En estos puntos, las legislaciones de los diversos Estados presentan variaciones; por ello, haremos las precisiones al efecto.

\section{El objeto del acuerdo: ¿acto inmoral, acto ilícito o delito?}

En el Derecho inglés ${ }^{41}$ de final del siglo XVIII, la idea general era que el acuerdo para cometer un acto ilícito (unlawful act) podía ser una conspiración criminal, donde unlawful act significaba algo más amplio que simplemente criminal ${ }^{42}$. En otras palabras, en aquella época un acuerdo podía ser calificado como criminal a pesar de que los actos objeto del acuerdo no eran criminales en ausencia del acuerdo ${ }^{43}$. De este

39 George P. Fletcher. Rethinking Criminal Law, New York, Oxford University Press, 2000, pp. 218-219.

40 La legislación de Inglaterra y Gales, sin embargo, prescribe la excepción a aquella regla en la que una persona no puede ser considerada culpable de conspiracy solo si el otro conspirador es su esposo/a, una persona que no alcanza la edad de responsabilidad penal (inimputable) o la pretendida víctima del delito acordado (Almir MALjevic. "Participation in a Criminal Organization" and “Conspiracy”. Different Legal Model Against Criminal Collectives. Berlin: Duncker \& Humblot. 2011, p.102).

41 Sistema jurídico aplicable a Inglaterra y a Gales.

42 Robert Hazell. Conspiracy and civil liberties: a memorandum submitted to the Law commission by the Cobden Trust and the National Council for Civil Liberties, London, Bell, 1974, p. 15.

43 Geoffrey Robertson. Whose Conspiracy?, London, National Council for Civil Liberties, 1974, p. 14. 
modo, la aplicación de la conspiración fue ampliada más allá de las fronteras de lo que se considera, en sentido estricto, "delito penal" (criminal offence) ${ }^{44}$. Esta postura doctrinal puede hallarse en el pronunciamiento de Lord Denman (1832), en el cual dice que "una conspiración criminal consiste en una combinación para lograr un fin ilícito, o un fin lícito por medios ilícitos", dejando abierta la cuestión del preciso significado de la palabra "ilícito" (unlawful) ${ }^{45}$. Esta sentencia ha sido aceptada y citada por jueces y cortes en numerosos $\operatorname{casos}^{46}$, el problema de esta sentencia reside en el hecho de que extiende el alcance de la conspiracy mucho más allá de los actos ilícitos ${ }^{47}$, al campo de los actos lícitos, borrando, de este modo, la línea entre ambos y creando espacios para interpretaciones erróneas y usos abusivos de la figura delictiva en cuestión. Dicho con otras palabras, en el Common Law la conspiracy era un acuerdo entre dos o más personas para hacer un acto ilícito, o hacer un acto lícito por medios ilícitos. Así, no era necesario probar que había un acuerdo para cometer un delito; acuerdos para cometer otros actos ilícitos, como el fraude, algunos agravios o corrupción de valores morales, claramente satisfacían las exigencias en cuanto al objeto. La Criminal Law Act 1977 pretendió limitar la conspiracy, primariamente, para acuerdos para cometer delitos penales. Sin embargo, temiendo que se podían crear lagunas y pendiente de una comprensiva revisión de la ley de fraude, obscenidad e indecencia, la ley de 1977 mantuvo determinadas conspiraciones del Common $L a w^{48}$. Así, en el sistema inglés conviven dos tipos de conspiraciones: la statutory conspiracy, o sea la tipificada por la ley de 1977, y las conspiraciones del Common Law, ejemplos de esta última son las conspiraciones para defraudar, para corromper la moral pública o ultrajar la decencia pública ${ }^{49}$.

De acuerdo con la ley de 1977, enmendada por la Criminal Attempts Act 1981, el objeto de la conspiracy debe ser o, mejor dicho, los conspiradores deben acordar: "1. un comportamiento a ser ejecutado; 2. que, si es llevado a cabo de acuerdo con sus intenciones; 3. necesariamente significará o comprenderá la comisión de un

44 Almir Maljevic. "Participation in a Criminal Organization” and "Conspiracy”. Different Legal Model Against Criminal Collectives, Duncker \& Humblot, Berlin, 2011, p. 72.

45 DAvid Harrison. Conspiracy as a Crime and as a Tort in English Law, London, Sweet \& Maxwell, 1924, p. 23.

46 Por ejemplo, R v. Seward (1834), O’Connell v. Regl (1884), Mulcahy v.s Reg. (1868), Quinn v. Laethem (1901), entre otros.

47 Esta dicotomía de tradición kantiana entre Derecho y moral ha sido seguida por la tradición germánica en la que el Derecho habla de cuestiones jurídicas y la moralidad de la cuestión del deber autoimpuesto. Sin embargo, como señala Fletcher, en la tradición de habla inglesa la moralidad tiene un sentido más amplio, incluso a veces ilimitado, siendo dicha línea de división difusa. GEORGE P. FLETCHER. Gramática del Derecho penal, traducción castellana de Francisco Muñoz Conde, Buenos Aires, Hammurabi, 2008, p. 264.

48 C. M.V. Clarkson, H. M. Keating, S. R. Cunningham. Clarkson and Keating Criminal Law: Text and Materials, $6^{\mathrm{a}}$ edición, London, Sweet \& Maxwell, 2007, p. 519.

49 C. M.V. Clarkson, H. M. Keating, S. R. Cunningham. Clarkson and Keating Criminal Law: Text and Materials, $6^{\mathrm{a}}$ edición, London, Sweet \& Maxwell, 2007, p. 519. 
delito". De este modo, los autores deben acordar los elementos básicos de su plan para cometer el delito, que debe comprender las consecuencias (v.gr. la muerte), lo que presupone que cada conspirador tiene la intención de que el delito acordado sea cometido ${ }^{50}$. No existen demasiados requerimientos en torno a los elementos del acuerdo, ni la ley ni las cortes han definido con precisión qué constituye un acuerdo completo. Muy probablemente, un acuerdo, en el sentido del delito de conspira$c y$, no tiene que ser un acuerdo entendido en sentido estricto, en los términos del contrato civil. A los efectos del delito, el acuerdo existe si al menos dos partes en plena disposición de sus facultades alcanzan una decisión cuyo elemento principal es alcanzar algún objeto ilícito. De acuerdo con el punto 3 mencionado, no significa que el delito de hecho será cometido, porque quizás la comisión del mismo es casi imposible, ni tampoco significa que los conspiradores tienen que saber que su conducta, junto a las consecuencias, constituyen un delito penal. Lo trascendente es si el plan, si es llevado con éxito, significaría o comprendería alguna actividad que la ley define como delito penal. Según la ley, una conspiración penal existe solo cuando el acuerdo, si es llevado a cabo de acuerdo con la intención de los acusados, necesariamente significa o comprende la comisión de un delito o de delitos por una o más partes del acuerdo. Por lo tanto, debe ser probado que al menos uno de los conspiradores se propone participar en la comisión del delito acordado como principal $^{51}$. Por otro lado, desde la ley de 1975, en Inglaterra y Gales, solo pueden ser objeto de la statutory conspiracy delitos penales (criminal offences), dejando atrás la jurisprudencia que avalaba la existencia del delito de conspiración incluso cuando su objeto no fuera ilícito, sino simplemente inmoral.

En resumen, en el Derecho inglés, la statutory conspiracy cuenta con dos elementos: el acuerdo de cometer un delito penal que es el elemento objetivo (actus reus) ${ }^{52}$, y la intención de acordar con otra persona para llevar adelante el delito pretendido, constituyendo este el elemento subjetivo (mens rea ${ }^{53}$. La distinción de ambos elementos del delito de conspiracy no es siempre una cuestión sencilla, debido a que el acuerdo en sí mismo es considerado esencialmente un acto mental. El mens rea del delito en cuestión exige que cada conspirador conozca los hechos o circunstan-

50 Almir Maljevic. "Participation in a Criminal Organization” and "Conspiracy”. Different Legal Model against Criminal Collectives, Duncker \& Humblot, Berlin, 2011, pp. 81-82.

51 Almir Maljevic. "Participation in a Criminal Organization” and "Conspiracy”. Different Legal Model against Criminal Collectives, Duncker \& Humblot, Berlin, 2011, p. 84.

52 En todos los delitos el actus reus es el elemento externo del mismo, el requerimiento objetivo necesario para constituir un delito. C. M.V. Clarkson, H. M. Keating, S. R. Cunningham. Clarkson and Keating Criminal Law: Text and Materials, $6^{\mathrm{a}}$ edición, London, Sweet \& Maxwell, 2007, p. 77.

53 El mens rea puede ser definido como el estado mental, o en el caso de la negligencia como el fracaso de alcanzar cierto estándar de comportamiento, requerido por la definición del delito. El mens rea es, a veces, definido de manera negativa, como el remanente del delito una vez que el actus reus ha sido sustraído. Cabe aclarar que las dos partes del delito (actus reus y mens rea) no existen separadamente. El mens rea cualifica el actus reus. Michael JefFERSOn. Criminal Law, $11^{\text {a }}$ edición, London, Pearson, 2013, p. 44. 
cias en relación con la finalidad del acuerdo, y debe pretender ser parte del acuerdo, procurando también que su delito fin sea llevado a cabo.

En el caso del Derecho penal de los EE.UU. la cuestión se torna más dificultosa. Si bien han heredado el delito de conspiracy por su pertenencia al sistema del Common Law, el hecho de que existan tantos Derechos penales como estados federados, torna arduamente dificultoso el análisis de esta figura delictiva. El delito federal de conspiracy desempeña un rol fundamental en el castigo de conductas delictivas incompletas en delitos de cuello blanco, tráfico de estupefacientes y, más recientemente, en casos de terrorismo. El mismo ha sido promulgado por ley del congreso como general criminal conspiracy statute USCA $18 \S 371$, que considera delictiva la conspiración de cometer cualquier delito contra los EE.UU. o defraudar a los EE.UU. También en el Derecho penal de los EE.UU., la conspiracy ha sido utilizada para imputar cargos que, de no mediar esta figura, no podrían ser considerados delitos. Sin embargo, el Código Penal Modelo, si bien no tiene vigencia puesto que el Congreso no lo ha adoptado como ley federal, restringe el ámbito de aplicación de la conspiracy a acuerdos cuya finalidad sea cometer delitos.

Además, previsiones en otras leyes federales criminalizan la conspiración para cometer determinados delitos. La mayoría de los tipos penales de conspiracy han sido ampliamente restringidos, usualmente exigiendo para su criminalidad la exigencia de un acto manifiesto (overt act $)^{54}$. En resumen, de acuerdo con la ley federal, la mayoría de las conspiraciones cuentan con tres elementos: a) un acuerdo para llevar adelante un acto ilícito (actus reus), b) con la intención de realizar el objeto del acuerdo (mens rea) y c) la comisión de un acto por uno o más miembros de la conspiración dirigido hacia la realización del objeto de la conspiración (overt act).

\section{Perfeccionamiento de la conspiracy: ¿mero acuerdo o exigencia de un acto manifiesto?}

En este punto difieren el Derecho inglés y el de los EE.UU. En el caso de la conspiracy en Inglaterra y Gales el delito se configura una vez que el acuerdo ha sido realizado y no es necesario probar otro acto manifiesto como elemento del delito. Se sostiene que la exigencia de un acto manifiesto en persecución del fin delictivo frustra el propósito preventivo del delito de conspiracy al tener que esperar hasta que el mismo se perfeccione para que se puedan imputar los cargos por el delito en cuestión ${ }^{55}$.

En el caso del Derecho penal de los EE.UU. la cuestión varía en función de los diversos estados federados; no obstante, en su mayoría, se exige el requisito de un acto

54 Juliet R. Amenge Окотн. The Crime of Conspiracy in International Criminal Law, Heidelberg, Springer, 2014, p. 25.

55 Michael Jefferson. Criminal Law, 11ª edición, London, Pearson, 2013, p. 407. 
manifiesto en cumplimiento del acuerdo para que el delito de conspiración quede perfeccionado. Una porción significativa del Código Penal Modelo ha sido adoptada por varios estados federados como instrumento interpretativo y para zanjar vacíos legales ${ }^{56}$. En lo que respecta al delito aquí tratado, en su artículo 5.03 establece: "Acto manifiesto. Ninguna persona puede ser condenada por conspiración para cometer un delito (...) a menos que un acto manifiesto en cumplimiento de tal conspiración es alegado y probado haber sido realizado por el o por la persona con quien conspiró".

Dado que el artículo antes mencionado no tiene vigencia, en el Derecho penal de los EE.UU. la regla sigue siendo que un hecho es punible como conspiración incluso cuando ningún acto haya sido realizado más allá del mero acuerdo, puesto que no existe ley que establezca lo contrario. Aunque, en la actualidad, la mayoría de los estados federados exigen la prueba de un acto manifiesto en cumplimiento del acuerdo o específicas finalidades conspiracionales. Ha sido objeto de discusión si el acto manifiesto era un elemento objetivo de la conspiracy o un mero elemento probatorio de la existencia del acuerdo, hoy en día tanto la doctrina como la jurisprudencia se inclinan por la primera interpretación. El acto manifiesto no necesariamente debe ser un acto ilícito, sino que basta con que sea un comportamiento en cumplimiento del acuerdo criminal alcanzado. En algunos estados federados, sin embargo, se exige que el acto manifiesto sea "un paso sustancial" en la comisión del delito acordado ${ }^{57}$. En el nivel federal ${ }^{58}$, por su parte, el acto manifiesto es específicamente exigido por la ley general de conspiracy ${ }^{59}$.

\section{La pluralidad de cargos: conspiracy y delito fin. La controversial doctrina Pinkerton}

Tanto el Derecho penal inglés como el de los EE.UU. posibilitan, en caso de que el acuerdo delictivo haya sido ejecutado, imputar tanto el delito fin como el delito de conspiracy. De este modo, la conspiración, en tanto "inchoate crime" o delito preparatorio ${ }^{60}$, no es absorbida por el delito fin, sino que son tratados de manera indepen-

56 La sección 5.03 del mismo establece que acordar con otra persona cometer un delito o la tentativa de cometerlo o la incitación a cometer un delito, o acordar ayudar a una persona en la planificación o en la comisión o en la tentativa o en la incitación a cometer tal crimen, lo hace responsable por conspiración.

57 Wayne R. LaFave. Criminal Law, $5^{\text {a }}$ edición, Eagan, Minnesota, West Publishing, 2010, p. 661.

58 En Yates vs United States, la Corte afirmó que la racionalidad del requisito del acto manifiesto era mostrar que la conspiración está obrando y que no es un mero esquema mental de los autores. Para sostener la convicción de la conspiración, el acto manifiesto no tiene que ser ilegal, ni necesita ser un elemento sustantivo del delito (fin), solo requiere ser un paso hacia el objetivo criminal.

5918 USCA $\$ 371$.

60 El Derecho penal del Common Law interviene para castigar a personas que todavía no han cometido un delito. Los delitos que penalizan conductas antes de la comisión del delito (consumado o sustantivo) son llamados "inchoate offences". Existen tres casos de "inchoate offences": 1) asistir y motivar (la 
diente. Si comparte la misma naturaleza que la tentativa, lo lógico sería, que al igual que esta, el delito de conspiracy quedase desplazado por el delito fin ejecutado ${ }^{61}$.

A este problema se le suma la controvertida aplicación, en el Derecho penal de los EE.UU., de la doctrina Pinkerton al delito aquí tratado. En Pinkerton vs United States $^{62}$, la Corte Suprema de Justicia de los Estados Unidos de América sostuvo que un conspirador debe ser considerado responsable por los delitos penales cometidos por otro conspirador que están dentro del alcance de la conspiración, que son en apoyo de ella, y son razonablemente previsibles como una necesidad o consecuencia natural de la conspiración. Bajo esta doctrina, la distinción entre autores y partícipes resulta eliminada, y todo conspirador puede ser responsable por los múltiples delitos llevados a cabo por los conspiradores en cumplimiento de la conspiración ${ }^{63}$. Toda participación o contribución hace a uno autor por conspiración, y todos los partícipes son igualmente responsables por todas las acciones en cumplimiento de la conspiración. Esta doctrina es criticada por extender de manera demasiado amplia la responsabilidad penal, llevando consigo una fuerte presunción de culpabilidad por asociación. Ella socava el principio fundamental del Derecho penal que requiere que la responsabilidad sea fundada en la culpabilidad personal. Hacer culpable a un conspirador por actos que no ha tenido conocimiento, o control sobre los mismos, o de haberlo conocido los hubiese objetado, es imponer responsabilidad objetiva, una clara violación al principio versari in re illicita. Sin embargo, no todos los estados federados están a favor de esta doctrina y algunas cortes la han rechazado. Además, el Código Penal Modelo también la rechaza ${ }^{64}$.

\section{Valoración crítica}

La conspiración es un inchoate crime o delito preparatorio, que permite el castigo de personas que acuerdan cometer un delito inclusive si ellos nunca llevan adelante su plan o si son aprehendidos antes de alcanzar su objetivo. Es en este rol en el cual la conspiracy ha sido más fuertemente defendida. De hecho, casi la única justificación ofrecida por los redactores del Código Penal Modelo para mantener el delito fue

comisión de un delito), 2) la conspiracy, y 3) la tentativa (attempt). MichaEL JEFFERSON. Criminal Law, $11^{\text {a }}$ edición, London, Pearson, 2013, p. 390.

61 La tentativa y el delito consumado se encuentran, al menos en los sistemas penales que aplican la teoría del delito, en una relación de subsidiariedad material. Se habla de subsidiariedad material cuando al autor un ilícito puede serle imputado de diferentes formas. Aquí el ilícito menos grave es sustituido por el más grave. URS KINDHÄUSER. Strafrecht: Allgemeiner Teil, $4^{\mathrm{a}}$ edición, Nomos, Baden-Baden, 2009, p. 376.

62 United States v. Pinkerton, 328 U.S. 640 (1946), p. 646.

63 George P. Fletcher. Rethinking Criminal Law, New York, Oxford University Press, 2000, p. 660.

64 Juliet R. Amenge Oкотн. The Crime of Conspiracy in International Criminal Law, Heidelberg, Springer, 2014, p. 33 
el hecho de punir grupos que acuerdan conductas preparatorias que no pueden ser alcanzadas por el tipo de tentativa ${ }^{65}$.

Entre la conspiración y la tentativa existen grandes similitudes; de hecho, ambas son tratadas como inchoate crimes; sin embargo, existen diferencias entre ellas. Así, en la tentativa se debe demostrar que el autor ha realizado un paso esencial hacia la comisión del delito; y los actos preparatorios previos no son suficientes. El tipo de conspiración, por el contrario, es un delito anticipatorio que ataca actos en una etapa más temprana, pues se perfecciona al momento del acuerdo o, en algunas jurisdicciones, al momento de realizar el primer acto en cumplimiento del acuerdo por cualquiera de las partes. Sin embargo, la conspiración no está fundamentada solo en criterios preventivos, pues si fuera así sería ilógico fundamentar la punición por conspiración y por el delito objeto del acuerdo o bien, que la conspiración, en muchos casos, sea considerada más grave que el delito acordado. Aquí aparece la otra función de la conspiración, la criminalización de la actividad grupal ${ }^{66}$. Detrás de la conspiracy yace la idea de que es más grave el delito perpetrado por un grupo que si es llevado adelante por un autor individual. De acuerdo con la doctrina del general danger rationale, hay tres argumentos que deben ser tenidos en cuenta: 1) si muchas personas actúan de manera concertada, ellas producen un peligro social mayor que una personal individual; 2) la probabilidad de que muchas personas lleven a cabo sus intenciones es mayor ${ }^{67}$, y 3) muchas personas son más capaces de cometer delitos más complejos que una persona individual ${ }^{68}$. De este modo, al argumento anticipatorio se le suma el de la mayor peligrosidad representada por el colectivo frente al autor individual.

No solo es en el excesivo adelantamiento punitivo donde yacen las objeciones hacia la conspiracy. En este delito en particular, los elementos objetivos (actus reus) y el componente subjetivo ( $m e n s$ rea) son difíciles, cuando no imposibles, de diferenciar ${ }^{69}$.

65 Philip Johnson. “The Unnecessary Crime of Conspiracy” en Californian Law Review, vol. 61, issue 5, 1973, pp. 1.157.

66 Wayne R. LaFave. Criminal Law, $5^{\text {a }}$ edición, Eagan, Minnesota, West Publishing, 2013, p. 656.

67 La confianza de la cooperación de los conspiradores y el intento de apoyarlos y ayudarlos en el futuro aumenta la probabilidad de conductas criminales por parte de los conspiradores. Harvard Law Review Association. "The Conspiracy Dilemma: Prosecution of Group Crime or Protection of Individual Defendants" en Harvard Law Review, Vol. 62, n. ${ }^{\circ}$ 2, 2013, p. 283.

68 C. M.V. Clarkson, H. M. Keating, S. R. Cunningham. Clarkson and Keating Criminal Law: Text and Materials, 6 a edición, London, Sweet \& Maxwell, 2007,p. 517. AlmiR MALJEVIC. "Participation in a Criminal Organization” and “Conspiracy”. Different Legal Model Against Criminal Collectives, Duncker \& Humblot, Berlin, 2011, p. 76.

69 Un mero acuerdo para cometer un delito es contemplado como manifestación suficiente de una intención maliciosa (mens rea) constituye el actus reus de la conspiracy. C. M.V. Clarkson, H. M. Keating, S. R. Cunningham. Clarkson and Keating Criminal Law: Text and Materials, 6 a edición, London, Sweet \& Maxwell, 2007, p. 76. 
Por otro lado, el hecho de que la conspiracy, en tanto delito de planeamiento, sea tratado como delito autónomo y, en caso de ejecutarse el acuerdo, concurra con el delito fin, conlleva una doble valoración de un mismo hecho, en violación al principio del ne bis in idem.

Además, el hecho de que el objeto de la conspiración, o sea, el acuerdo, no esté especificado en sus requisitos, hace que su aplicación sea imprecisa, aumentando los márgenes de discrecionalidad y reduciendo las posibilidades de defensa. Especialmente en aquellas jurisdicciones, como en el caso de Inglaterra y Gales, en las que no es necesario un acto manifiesto en cumplimiento del fin delictivo para que la conspiración quede perfeccionada. También, como hemos visto, existen reparos respecto del objeto del acuerdo, en especial porque todavía pueden constituir objeto de conspiración actos no necesariamente ilícitos, sino meramente inmorales. ¿Por qué el Derecho penal debe extender ámbito de intervención más allá de la frontera de lo estrictamente ilícito (en términos de Unrecht)?

\section{El modelo "participación en una asociación criminal”}

Los países seguidores de la tradición alemana en materia de dogmática jurídico-penal comparten un tipo penal que, pese a sus variaciones en cada uno de los diversos sistemas, posee características altamente similares. Este tipo penal consiste en ser miembro o participar de una asociación destinada a cometer delitos. El grado de organización requerido para que exista una asociación, así como las conductas típicas que, más allá de la acción de participación en calidad de miembro de la asociación, quedan comprendidas dentro de este delito (v.gr. fundar, promover, administrar, financiar, hacer propaganda, apoyar, etc.) varían entre los diversos sistemas jurídicos que poseen este tipo penal.

Está claro que el delito en cuestión no es un fenómeno que entrañe ninguna novedad para el Derecho penal, pues este tipo penal no surge como consecuencia de la modernidad tardía, sino que ya estaba presente en las diversas legislaciones al momento de proliferación de los llamados “delitos de organización”. Ya el Derecho penal clásico ha tenido que lidiar con tipos penales cuyo objeto de protección (en términos de bien jurídico protegido) resulta difuso y, el caso de la asociación criminal, delictiva o ilícita no es ajeno a ello.

En el delito objeto de análisis, el autor es responsable por participar de una organización destinada a cometer delitos, es decir, por ser miembro de la misma. ¿Qué intereses son protegidos por este tipo penal? La pregunta en cuestión ha suscitado un interesante debate en la doctrina alemana, no existiendo unanimidad al respecto. Tanto la jurisprudencia como la doctrina tienen diversas opiniones sobre qué intereses están o deben estar protegidos por el tipo penal de asociación criminal ( $\$ 129$ StGB). El delito en cuestión está emplazado la sección séptima de la parte especial del StGB titulado "Hechos punibles contra el orden público". Esto significa que el 
legislador era de la opinión de que el interés general a ser tutelado por el §129 es el orden público. Desgraciadamente, como señala con acierto Langer-Stein, el orden público, como término, puede ser visto desde el punto de vista del Derecho de policía, desde el punto de vista del Derecho penal, desde el punto de vista político, etc., y, por lo tanto, no puede ser entendido y considerado como el bien jurídico específico protegido por el $\S 129^{[70]}$. No obstante esta apreciación, la jurisprudencia alemana ha aceptado esta comprensión del bien jurídico protegido, en términos exactos o con palabras ligeramente modificadas, y se ha referido a él como "orden público"71, "seguridad interna"72, "orden y seguridad interna"73 o bien, "seguridad pública"74. Alguna parte de la doctrina acepta esta aproximación y afirma que la interpretación apropiada es "orden y seguridad pública del Estado"75 o simplemente "seguridad pública interna"76.

La fundamentación basada exclusivamente en la afectación de un bien jurídico colectivo por parte de la asociación no resulta, sin embargo, satisfactoria dado que, si considerásemos al delito de organización como delito por adhesión o de pertenencia, deberían desarrollarse criterios para fundamentar el traslado de la responsabilidad de la organización en una punición de los autores individuales que formaren parte de ella. Dichos criterios deberían ser idóneos para responder la siguiente pregunta: ¿bajo qué criterios el hecho de pertenecer a una organización delictiva redunda en una imputación a la persona individual?

La dogmática jurídico-penal alemana ha intentado otra solución bajo el título de "teoría de la anticipación" (Vorverlagerungstheorie) que ha justificado la existencia de la organización en tanto delito autónomo, considerando al delito asociativo como una anticipación (acto preparatorio) del delito fin de la asociación. Para Rudolphi, en tanto delito autónomo, el §129 no protege ningún bien jurídico por sí mismo. Tomando la extensión de la punibilidad bajo el $§ 129$ a actos preparatorios como punto de partida, argumenta que la peligrosidad de la asociación criminal es considerada en la posibilidad que delitos, cuya comisión es la finalidad o actividad de la asociación, sean realmente cometidos. Por lo tanto, el $§ 129$ protege aquellos bienes jurídicos protegidos por los tipos penales de la parte especial del Código Penal hacia los cuales

70 Rose LANGER-STEIn. Legitimation und Interpretation der strafrechtlichen Verbote krimineller und terroristischer Vereinigungen ( $\$ 129,129$ a StGB), München, Florentz, 1987, p. 110.

71 BGH v. 12.10.1965, NJW 1966, p. 310, p. 312.

72 BGH v. 12.02.1975, NJW 1975, p. 985.

73 BGH v. 05.01.1982, NJW 1982, p. 530.

74 BGH v. 22.02.1995, NJW 1995, pp. 2117-2118.

75 Klaus Miebach, Jürgen Schäfer. “\$ 129” en Klaus Miebach (ed.) Münchener Kommentar zum Strafgesetzbuch, $3^{\text {a }}$ edición, München, C. H. Beck, Tomo 3, 2017, p. 615.

76 Eckhart von Bubnoff. “\$ 129” en Burkhard JÄnKe et al. (eds.) Strafgesetzbuch. Leipziger Kommentar, $11^{\text {a }}$ edición, Berlin, Walter de Gruyter, Tomo 4, Rn. 1, 1995, p. 127. 
están dirigidos los dirigidos delitos fin ${ }^{77}$. Todo esto significa que, en términos de sus consecuencias, el $\S 129$ es un delito que también criminaliza un peligro abstracto $^{78}$. Tanto la doctrina como la jurisprudencia han aceptado la existencia de delitos de anticipación o preparación, mediante los cuales son sancionados actos preparatorios con carácter excepcional, sobre la base de una intervención temprana en el hecho que, de no ocurrir en ese momento, la pena perdería toda eficacia ${ }^{79}$. Tanto la doctrina como la jurisprudencia del $\mathrm{BGH}^{80-81}$ concuerdan en que, teniendo en cuenta los elementos del delito, la introducción del delito de asociación criminal (\$129 StGB) extiende la punibilidad a etapas preparatorias de delitos penales. Esto es explicado por el hecho de que las asociaciones criminales, cuyas actividades están dirigidas hacia la comisión de delitos, representan un peligro incrementado para los bienes jurídicos que el Estado y sus ciudadanos quieren estar protegidos. Su peligrosidad no solo deriva del hecho que los miembros de la asociación quieren cometer delitos, sino también fuera de la dinámica interna de la asociación, ya que reduce o inclusive excluye el sentimiento de responsabilidad individual de los miembros y hace más fácil la comisión de delitos ${ }^{82}$. Rudolphi destaca la naturaleza preventiva de este tipo penal, asignándole la función de prevenir los peligros que la asociaciones criminales representan para los bienes jurídicos y, así, desmantelar una fuente de peligro significativo. Estamos ante un tipo penal preventivo cuya función es combatir el delito en una etapa preparatoria ${ }^{83-84}$.

77 HANS-JOACHIM RudOLPHI. ,Verteidigerhandeln als Unterstützung einer kriminellen oder terroristischen Vereinigung i. S. der §§ 129 a StGB“ en Festschrift für H.J. Brums zum 70. Geburtstag, Köln: Heymann, 1978, pp. 317-318.

78 En igual sentido: Rose LANGER-STEIN. Legitimation und Interpretation der strafrechtlichen Verbote krimineller und terroristischer Vereinigungen (\$§ 129, 129a StGB), München: Florentz, 1987 , p. 211.

79 Jans-HeinRich JeSCHECK, Thomas WeIGEND. Lehrbuch des Strafrechts. Allgemeiner Teil, 5 a edición, Duncker \& Humblot, Berlin, 1996, pp. 523-524.

80 ECKHART VON BuBNOFF. “\$ 129” en BuRKHARD JÄNKE, ET AL (eds.) Strafgesetzbuch. Leipziger Kommentar, $11^{\text {a }}$ edición, Berlin, Walter de Gruyter, Tomo 4, 1995, Rn. 1, p. 126. HANS-JOACHIM RudOLPHI, UlRICH STEIN. „\$129“ en JÜRGEN WOLTER (ed.) Systematischer Kommentar zum Strafgesetzbuch, $8^{\mathrm{a}}$ edición, Köln, Carl Heymanns, Rn. 3, 2012, p. 5.

81 BGH v. 11.10.1978, NJW 1979, pp. 172-173; BGH v. 22.02.1995, NJW 1995, p. 2117; BGH 21.10.2004, NJW, 2005, pp. 80-81.

82 Almir Maljevic. "Participation in a Criminal Organization" and "Conspiracy”. Different Legal Model Against Criminal Collectives, Duncker \& Humblot, Berlin, 2011, p. 34.

83 HANS-JOACHIM RudOLPHI. ,Verteidigerhandeln als Unterstützung einer kriminellen oder terroristischen Vereinigung i. S. der §§ 129 a StGB“ en Festschrift für H.J. Brums zum 70. Geburtstag, Köln, Heymann, 1978, p. 317. En igual sentido: Hans-JoACHIM RudolPHI. ,Notwendigkeit und Grenzen einer Vorverlagerung des Strafrechtsschutzes im Kampf gegen den Terrorismus“ en Zeitschrift für Rechtspolitik, 1979, cuaderno 9, 1979, pp. 215.

84 También basado en argumentos preventivos Maurach había afirmado que la fundamentación de la punición de los miembros y colaboradores de la organización criminal radicaría en su manifiesta enemistad al Derecho (offene Rechtsfeindschaft). REINHART MAuraCH. Strafrecht: Besonderer Teil,

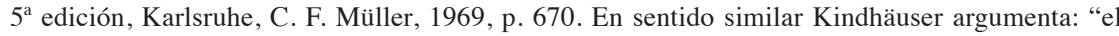


Para Jakobs, en el delito de asociación criminal el fundamento de punición no reside en la lesión de un bien jurídico colectivo. La conducta tipificada no sería peligrosa en absoluto o solo lo sería de manera muy limitada sin un comportamiento sucesivo de naturaleza delictiva. Ella en sí misma es la preparación de un delito posterior. Se trata de una lesión meramente parcial que no infringe normas principales (Hauptnormen), es decir aquellas que garantizan expectativas normativas sino normas de flanqueo (flankierende Normen) cuya misión es garantizar las condiciones de vigencia de las normas principales ${ }^{85}$. En el modelo comunicativo de Jakobs, la vigencia de la norma no solo depende de la confianza (negativa) que de ella tengan los potenciales autores, sino una cuestión multifacética en la que interviene la confianza (positiva) de los potenciales afectados y es en esta última dimensión donde las normas de flanqueo despliegan su función. En el caso de la asociación criminal, la conducta es ilícita porque existe una drástica elevación del riesgo desde la perspectiva de la potencial víctima, dificultando la vigencia de la norma para este ${ }^{86}$. Dado que existe lesión de la norma de flanqueo en la medida que el autor da a entender que próximamente tendrá lugar una perturbación externa, pero no existe aún lesión de una norma principal, puesto que el plan delictivo no se ha llevado todavía a cabo, la pena para la conducta incriminada tiene que tener en cuenta qué tipo de norma ha sido lesionada ${ }^{87}$.

\section{La estructura del delito de asociación criminal en el Derecho penal alemán}

Conforme al §129 StGB, “(1) Quien forme una asociación criminal cuyo objeto o cuya actividad esté orientada a la comisión de hechos, o quien participe en una tal asociación como miembro, haga propaganda para ella o la apoye, será castigado con pena privativa de la libertad hasta cinco años o con multa”.

autor, en la medida que quiere ponerse en situación de cometer un hecho antijurídico, se convierte en un riesgo para la seguridad". URS KINDHÄUSER. Gefährdung als Straftat: rechtstheoretische Untersuchungen zur Dogmatik der abstrakten und konkreten Gefährdungsdelikte, Frankfurt am Main, Klostermann, 1989, p. 315. De una manera más radical Jakobs sostiene que "Ya una mirada muy superficial al StGB pone de manifiesto que numerosos preceptos caen fuera del marco de lo que aquí se denomina Derecho penal de ciudadanos y pertenecen al Derecho penal de enemigos, en concreto todas las criminalizaciones de lo que materialmente son actos preparatorios, en la medida en que la conducta preparatoria se efectúe en el ámbito privado (...) pertenecen a este ámbito algunos delitos contra la seguridad del Estado, así como la constitución de asociaciones criminales o terroristas ( $\S \S$ 129 y 129 a StGB)”. GÜNTHER JAKOBS. „Kriminalisierung im Vorfeld einer Rechtsgutsverletzung“ en: Zeitschrift für die gesamte Strafwissenschaft, vol. 97,1985, pp 756-757.

85 GÜNTHER JAKOBS. „Kriminalisierung im Vorfeld einer Rechtsgutsverletzung“ en Zeitschrift für die gesamte Strafwissenschaft, vol. 97, 1985, p. 775.

86 GÜNTHER JAKOBS. „Kriminalisierung im Vorfeld einer Rechtsgutsverletzung“ en Zeitschrift für die gesamte Strafwissenschaft, vol. 97, 1985, p. 775.

87 GÜNTHER JAKOBS. „Kriminalisierung im Vorfeld einer Rechtsgutsverletzung“ en Zeitschrift für die gesamte Strafwissenschaft, vol.97, 1985, pp. 778-779. 
El Código Penal alemán no define "asociación criminal". No obstante, la jurisprudencia y la doctrina definen este concepto muy claramente como una unión organizada, existente por cierto periodo de tiempo, de al menos tres personas que, subordinando su voluntad individual a la voluntad de la unión, persigue sus juntas finalidades criminales y los miembros están en tan mutua relación que ellos sienten que pertenecen a la unión ${ }^{88-89}$.

Para que exista una asociación de este tipo se requiere de la conexión de al menos tres personas. Si bien el StGB no estipula el número de mínimo de miembros que debe poseer una asociación, el BGH interpretó que no puede haber asociación criminal si no están involucradas más de dos personas ${ }^{90}$. Este conjunto de personas tiene que estar asociado de tal manera que formen una unión. Esto presupone que los miembros de la asociación subordinan sus voluntades individuales a la voluntad de la asociación ${ }^{91}$. Adicionalmente, los miembros tienen que definir conjuntamente los fines de la asociación y tienen que obligarse mutuamente, ya sea explícitamente o por sus acciones, para conseguir dichos objetivos. "Obligarse" no debe ser entendido aquí en el sentido legal del término, sino en términos de aceptar a contribuir al logro de los fines de la asociación mediante la realización de ciertos roles. Los miembros deben estar coordinados representando así un esfuerzo conjunto conducente a cumplir los fines de la asociación. Todo esto significa que una asociación criminal requiere un cierto mínimo de organización interna. Los elementos organizacionales de la aso-

88 Klaus Miebach, Jürgen SchäFer. “\$ 129” en Klaus Miebach (ed.) Münchener Kommentar zum Strafgesetzbuch, $3^{\text {a }}$ edición, München, C. H. Beck, Tomo 3, 2017, p. 622. ECKHART von BubnOFF. “\$ 129” en BuRKHARD JÄNKE et al. (eds.) Strafgesetzbuch. Leipziger Kommentar, $11^{\text {a }}$ edición, Berlin, Walter de Gruyter, Tomo 4, 1995, p. 118. HANS-JOACHIM RUdOLPHI, UlRICH STEIN. „§129“ en JÜRGEN WOLTER (ed.) Systematischer Kommentar zum Strafgesetzbuch, $8^{\mathrm{a}}$ edición, Köln, Carl Heymanns, Rn. 5, 2012, p. 6.

89 BGH v. 11.10.1978, NJW, 1979, p. 172; BGH v. 02.02.1983, NJW 1983, p. 1686; BGH v. 13.01.1983, NJW 1983, p. 1334; BGH v, 10.03.2005, NJW 2005, p. 1668 (1670); BGH v. 10.01.2006, NJW 2006, p. 1603.

90 BGH 11.10.1978, NJW 1979, pp. 172-173. Rudolphi rechaza la idea de que un grupo de tres o cuatro personas pueda desplegar, salvo raras excepciones, una dinámica propia que promueve y favorezca, de una manera especial, la comisión de los delitos planeados a través de sus miembros. HANS-JOACHIM RudOLPHI (1978). ,Verteidigerhandeln als Unterstützung einer kriminellen oder terroristischen Vereinigung i. S. der $\$ 129$ a StGB“ en Festschrift für H.J. Brums zum 70. Geburtstag, Köln, Heymann, p. 320 .

91 Klaus Miebach, JÜRGEN SchÄFER. “\$ 129” en Klaus Miebach (ed.) Münchener Kommentar zum Strafgesetzbuch, $3^{\text {a }}$ edición, München, C. H. Beck, Tomo 3, 2017, p. 622. Este prerrequisito no es cumplimentado si los miembros de la asociación subordinan su voluntad individual a la voluntad de una persona líder de la organización. Esto es así porque la voluntad de los miembros está subordinada a la voluntad de una sola persona, y no a la voluntad de la mayoría de los miembros de la asociación, faltando así el sentimiento de pertenencia a una unión. Esto, sin embargo, no se aplica si la mayoría de los miembros decidieron conceder a una persona la permisión de tomar decisiones y, de ese modo, crea la voluntad de la asociación a la que los otros miembros subordinan su voluntad individual. Almir Maljevic. "Participation in a Criminal Organization" and "Conspiracy". Different Legal Model Against Criminal Collectives, Duncker \& Humblot, Berlin, 2011, p. 103. 
ciación se encuentran en el trabajo conjunto de al menos tres personas, con roles divididos basados en las reglas establecidas dentro de la asociación ${ }^{92}$.

Por otro lado, la asociación criminal tiene un objetivo criminal específico, que no es otro que el de cometer delitos de cualquier tipo. Solo pueden ser objeto de la asociación delitos penales comprendidos en el Código Penal o en leyes penales especiales. Se excluyen así asociaciones cuyo objeto se cometer meras contravenciones u otra clase de ilícitos que no posean naturaleza penal. El hecho de que la asociación deba tener una finalidad criminal no implica que el objeto de esta sea exclusivamente criminal o que la comisión de delitos sea su actividad principal. Es suficiente con que los delitos fin sean solo un medio para el logro de otro objetivo ${ }^{93}$. Tampoco es necesario que los delitos fin efectivamente se lleven a cabo.

Finalmente, una asociación tiene que existir por un cierto periodo de tiempo. A pesar de que este periodo de tiempo no ha sido definido, se sostiene que debe estar determinado basado en dos criterios. Primero, una asociación criminal ciertamente debe existir por más tiempo que el requerido para que una operación criminal compleja sea planificada y ejecutada. En segundo lugar, la duración de esta existencia requiere ser lo suficientemente larga así que, bastada en la estructura interna de la asociación y las relaciones mutuas entre sus miembros, puede ser establecida una dinámica interna de la asociación ${ }^{94}$.

En cuanto a las formas de participación en una asociación criminal, el StGB estipula cuatro modos diversos de participación. En primer lugar, aparecen descritos los fundadores, como una asociación que interviene en la conclusión de la asociación a través de la participación en la planificación o en el desarrollo de los acuerdos ${ }^{95}$. Un fundador no necesariamente tiene que tornarse miembro de la asociación fundada, pudiendo limitarse únicamente a aquel acto $^{96}$. En segundo lugar, están los miem-

92 Klaus Miebach, JÜrgen Schäfer. “\$ 129” en Klaus Miebach (ed.) Münchener Kommentar zum

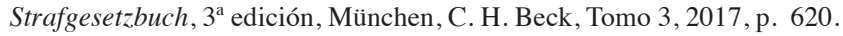

93 BGH v. 21.12.1977, NJW 1978, p. 433; BGH v. 22.02.1995, NJW 1995, pp. 2117-2119.

94 Almir Maljevic. "Participation in a Criminal Organization” and "Conspiracy”. Different Legal Model Against Criminal Collectives, Duncker \& Humblot, Berlin, 2011, p. 104.

95 HANS-JOACHIM RUdOlPHI, UlRICH STEIN, „§129“ en JÜRGEN WOLTER (ed.) Systematischer Kommentar zum Strafgesetzbuch, $8^{a}$ edición, Köln, Carl Heymanns, 2012, Rn. 14, p. 17.

96 Para Rudolphi y Stein, esta no es una forma esencial de participación. El fundador no necesariamente es un miembro líder u orientador. Solo esta interpretación restrictiva del concepto de fundador posibilita una exacta aplicación del §129 párrafo 4 StGB, de acuerdo con el cual la escala penal es más elevada para el líder (Rädelsführer) que para el hombre de atrás (Hintermann) de la asociación, y del párrafo 5 según el cual el tribunal puede abstenerse de imponer toda pena donde el grado de culpabilidad o de participación sea menor. HANS-JoACHIM RUdOLPHI, UlRICH STEIN (2012). „§129“ en JÜRGEN Wolter (ed.) Systematischer Kommentar zum Strafgesetzbuch, $8^{\mathrm{a}}$ edición, Köln, Carl Heymanns, Rn. 14, p. 17. En contra, siguiendo la opinión mayoriataria, para Bubnoff el miembro fundador es aquella persona que en el acto de fundación asume un rol de dirección y liderazgo. ECKHART VON 
bros de la asociación criminal, es decir, aquellos que se incorporan a la asociación, subordinan su voluntad a la voluntad de la asociación y participan de actividades de la asociación en línea con la realización de los fines de la misma. Una mera pertenencia pasiva no es suficiente, para adquirir la calidad de miembro debe participar de actividades dirigidas que están directamente dirigidas hacia la comisión de de$\operatorname{litos}^{97}$. La tercera forma de participación, de "hacer propaganda", consiste en una expresión de manera expresa o concluyente con el contenido directamente dirigido a ganar nuevos miembros o personas que apoyen la asociación ${ }^{98}$. La última de las formas de participación consiste en la actividad de apoyo de la asociación, la jurisprudencia considera a esta forma de participación como el conjunto de actividades directamente dirigidas al mantenimiento o realización de los fines de la asociación ${ }^{99}$. Rudolphi y Stein consideran, por el contrario, que la actividad de apoyo como el conjunto de actividades destinadas a mantener o aumentar el daño potencial que plantea la asociación ${ }^{100}$.

El delito en cuestión, en todas sus modalidades de participación, solo puede ser llevado a cabo de manera dolosa. Teniendo en cuenta la finalidad criminal de la asociación, y los medios que esta utiliza para alcanzar dicha finalidad, resulta difícil pensar una actuación dolosa que no fuese con dolo directo. No obstante, el BGH ha establecido que todas las antes señaladas, con la excepción de "hacer propaganda", pueden ser cometidas, incluso, con dolo eventual ${ }^{101}$. Forma parte del dolo que el autor conozca la finalidad de la asociación o que su actividad está directamente dirigida hacia la comisión de delitos.

\section{La asociación ilícita en el derecho penal argentino}

En el caso argentino, la figura básica de asociación ilícita está establecida en el artículo 210 del Código Penal dentro del título correspondiente a delitos contra el

BubnOFF. “\$ 129” en BurKhard JÄNKE, ET AL (eds.) Strafgesetzbuch. Leipziger Kommentar, 11 edición, Berlin, Walter de Gruyter, Tomo 4, 2005, p. 143.

97 Eckhart von Bubnoff. “§ 129” en Burkhard Jänke, ET AL (eds.) Strafgesetzbuch. Leipziger Kommentar, $11^{a}$ edición, Berlin, Walter de Gruyter, Tomo 4, 2005, p. 144. El delito consiste en ser miembro de una asociación criminal y no en la participación en delitos de la asociación criminal. Hans-JoAchim RudolPhi, UlRich Stein (2012). „§129“ en JÜRgen Wolter (ed.) Systematischer Kommentar zum Strafgesetzbuch, $8^{a}$ edición, Köln, Carl Heymanns, 2012, Rn. 16b, p. 19.

98 Hans-JoAchim RudolPhi, Ulrich Stein. „\$129“ en JÜRgEn Wolter (ed.) Systematischer Kommentar zum Strafgesetzbuch, 8 edición, Köln, Carl Heymanns, Rn. 18, 2012, p. 22.

99 BGH v. 25.07.1984, NJW 1984, pp. 2956-2957.

100 Hans-JoAchim Rudolphi, UlRich Stein (2012). „\$129“ en JÜRGEN Wolter (ed.) Systematischer

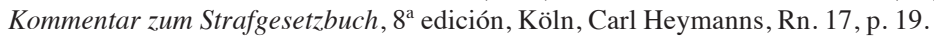

101 BGH v. 03.10.1979, NJW, 1980, p. 64. 
orden público ${ }^{102}$. Al respecto, estipula: "Será reprimido con prisión o reclusión de tres a diez años, al que tomare parte en una asociación o banda destinada a cometer delitos por el solo hecho de ser miembro de la asociación. Para jefes u organizadores de la asociación el mínimo de pena será de cinco a diez años de prisión o reclusión" (art. $210 \mathrm{CP})$.

El Código Penal argentino posee un tipo penal muy simple en lo que respecta a la asociación criminal. El tipo penal castiga al sujeto que toma parte de una asociación cuya finalidad sea cometer delitos, es decir, reprime la mera pertenencia a dicha asociación independientemente de si el autor ha intervenido o no en la comisión de algún delito fin. En tanto acto preparatorio del delito fin sancionado como delito autónomo, lo relevante es el hecho de asociarse. A su vez, distingue tres tipos de autores: los miembros, los jefes y los organizadores ${ }^{103}$. A estos dos últimos se les aplica una escala penal agravada.

No se exigen demasiados requisitos para establecer la existencia de una asociación ilícita. Conforme a la descripción típica tres son sus elementos básicos: a) la acción de asociarse o conformar una asociación de este tipo (tomar parte), b) un número mínimo de autores consistente en tres o más personas y c) el fin delictivo, consistente en cometer delitos en un número indeterminado ${ }^{104}$. Respecto del primer requisito consistente en tomar parte del a asociación, la mayoría de la doctrina no interpreta en el sentido formal, considerando suficiente el pacto de constitución o de adhesión

102 Para Soler, al hablar de orden público, nuestra ley penal quiere decir tranquilidad y confianza social en el seguro desenvolvimiento pacífico de la vida civil: SEBASTIÁN SOLER. Derecho Penal argentino. Buenos Aires: Tipográfica Editora Argentina, Tomo 4, 1992, pp. 696-697. Por su parte, D’Alessio considera que "El delito afecta en sí mismo la tranquilidad de la población en general, por cuanto el fenómeno de la delincuencia organizada implica, por esa sola circunstancia, una razonable amenaza para la seguridad personal y una mayor cuota de alarma social. La criminalidad de este delito no reside en la lesión efectiva de cosas o personas, sino en la repercusión que aquel tiene en el espíritu de la población y en el sentimiento de tranquilidad pública, produciendo alarma y temor por lo que puede suceder": José AndRÉs D’Alessio (director). Código Penal: comentado y anotado: parte especial (arts. 79 a 306). Buenos Aires, La Ley, 2004, p. 679.

103 Es jefe el que comanda o dirige la asociación, cualquiera sea el grado de participación en el ejercicio del mando, sin la obligación de rendir cuentas o requerir autorización. Pueden ser una o más personas. No es suficiente la jefatura ocasional o en un determinado hecho, y no se requiere que haya tomado intervención en la ejecución de los hechos que lideró. Por su parte, organizadores son los miembros de la asociación que han actuado en su establecimiento, ordenamiento o constitución: JosÉ ANDRÉs D'Alessio (director). Código Penal: comentado y anotado: parte especial (arts. 79 a 306). Buenos Aires, La Ley, 2004, p. 680-681). Para NúÑEZ y RUBIo, no encuadran en este concepto los promotores, que son los que inician o llevan adelante las gestiones tendientes a constituir la asociación sin formar parte de ella, y que -conforme alguna doctrina- solo podrán ser penados como instigadores del delito (RICARdo NúÑEZ. Tratado de Derecho Penal. Córdoba: Marcos Lerner Editora, Córdoba, tomo v, vol. I, 1992, p. 188; Zulma Lidia Rubio. El delito de asociación ilícita. Buenos Aires, Librería Editora Platense, 1981, p. 12).

104 En contra, considerando que el número indeterminado de delitos no es un requisito del tipo. EDGARDO Donna. Derecho penal: parte especial. Buenos Aires, Rubilzal Culzoni, Tomo II-C, 2002, p. 308. 
a la asociación ${ }^{105}$. En una postura minoritaria, que consideramos acertada, Ziffer sostiene que la mera incorporación formal a la asociación no es suficiente, pues

la calidad de 'miembro' se adquiere recién al 'tomar parte', y la participación como miembro presupone que el autor actúa de alguna forma en su calidad de tal. Afirmar que es 'miembro' de la asociación ilícita supone la realización de actividades con pretensión de permanencia, y que tales actividades tiendan a favorecer a la organización o que son típicas de la actividad social en alguna u otra forma relevante, o bien, cuando, a través de un actuar repetido dirigido a la realización de las acciones antijurídicas planeadas por la asociación, es posible que el autor ha asumido como propios los fines del grupo ${ }^{106}$.

La asociación ilícita exige cierto grado de permanencia derivada de su propio objeto, ya que la pluralidad delictiva que constituye su razón de ser "demanda una actividad delictiva continuada incompatible con una cooperación instantánea" 107 . Por otro lado, estamos ante un delito de naturaleza dolosa, según el cual el autor debe conocer que participa de una asociación con las características antes indicadas y debe tener la voluntad de permanecer a ella, con todas las reglas que la asociación tiene como estructura interna ${ }^{108}$.

\section{COMPARACIÓN DE MODELOS}

De manera no infrecuente conspiracy y "asociación criminal" son tratados como conceptos equivalentes pertenecientes a distintos sistemas jurídicos. Sin embargo, ello no es así por varios motivos. Si bien es cierto que los fundamentos de punición coinciden en ambos modelos, es decir, ambas categorías se fundamentan en criterios preventivos ligados a la mayor eficacia en la intervención anticipada del delito, como así también en la mayor peligrosidad que presenta el grupo frente al autor individual. No obstante, las similitudes en torno a su fundamentación, consideramos que el tipo de conspiracy no puede ser equiparado al de "asociación criminal", y si tiene algún equivalente en el sistema continental, quizás sea, salvando las diferencias, la tentativa de participación del $\$ 30 \mathrm{StGB}^{109}$, que no constituye un delito autónomo, sino que

105 Para D'Alessio el delito se consuma en el momento en que los autores se asocian para delinquir - por el simple hecho de formar parte de la asociación. José AndRÉs D’Alessio (director). Código Penal: comentado y anotado: parte especial (arts. 79 a 306), Buenos Aires, La Ley, 2004, p. 680.

106 PATRICIA ZifFer. El delito de Asociación ilícita, Buenos Aires, Ad-Hoc, 2005, 2005, pp. 70-71.

107 Jorge Boumpadre. Derecho penal: parte especial, T. II, Mario A. Viera Editor: Buenos Aires, 2001, p. 368.

108 Edgardo Donna. Derecho penal: parte especial. Buenos Aires, Rubilzal Culzoni, Tomo II-C, 2002 , p. 311.

109 § 30. Tentativa de participación: (1) Quien intente determinar a otro a cometer un crimen o instigarle a ello, será castigado conforme al precepto sobre tentativa de crimen. Sin embargo, se debe atenuar 
criminaliza una forma de participación en la comisión de un delito, representando una extensión de la punibilidad hasta las etapas más tempranas de preparación de un delito grave ${ }^{110}$, cuya constitucionalidad resulta harto dudosa ${ }^{111}$.

Las diferencias entre ambos modelos van más allá del número de personas requeridas para configurar una conspiración o una asociación criminal. El problema radica en que la conspiración supone un adelantamiento de punición que no resulta compatible con nuestro sistema de imputación jurídico-penal, y habilitar a que el Estado criminalice ese tipo de acuerdos implicaría una intromisión del poder punitivo en la esfera de privacidad de los particulares, especialmente si consideramos que el acuerdo criminal no necesariamente tiene que implicar la comisión de un delito grave, ni la certeza de que el mismo sea llevado a cabo. Tampoco la exigencia del acto manifiesto (overt act) en cumplimiento del acuerdo lo pone a resguardo de las críticas, en especial porque el mismo no necesariamente debe ser ilícito, sino solo un comportamiento de cualquier tipo que demuestre que el acuerdo ha comenzado a cumplirse (el primer acto en cumplimiento del acuerdo). Dicho con otras palabras, la conspiración queda consumada con el mero complot, y lo que se castiga es planear un delito entre dos o más personas. Se produce un excesivo adelantamiento de la punibilidad, no ya a la preparación sino al mero planeamiento de un delito con la sola limitación, en algunas jurisdicciones, que haya realizado un acto manifiesto, es decir, un acto revelador de la decisión común de ejecutar el delito acordado.

Similar crítica debe extenderse al delito de asociación criminal, especialmente en aquellas legislaciones, como es el caso de la argentina, donde el tipo penal es interpretado, en el sentido de que basta una mera adhesión o participación formal ("tomar parte") de tres o más personas, para que el delito se perfeccione. Para que

la pena según el § 49, inciso 1. El § 23 inciso 3 rige en lo pertinente. (2) Del mismo modo será castigado, quien se declare dispuesto; quien acepte el ofrecimiento de otro o quien con otro concierte para cometer un crimen o a instigar a él.

110 Claus Roxin. “\$ 30” en BurKhard JänKE et al. (eds.) Strafgesetzbuch. Leipziger Kommentar, 11 edición, Berlin, Walter de Gruyter, Tomo 1, 1994, Rn. 1, pp. 45-46.

111 EduARD KoHLRAUSCH, Richard LANGE. Strafgesetzbuch mit Erläuterungen und Nebengesetzen, $43^{\mathrm{a}}$ edición Berlin, Walter de Gruyter, 1961,pp. 187-189. Acertadamente Jakobs aclara: Si, por ejemplo, en la (...) tentativa de participación del $\S 30$ StGB se definen acuerdos previos como delitos, incluso si se realizan en condiciones de privacidad, v. gr. por personas entre las que media amistad, se priva a los intervinientes, en esa medida, de su ámbito interno y se les trata como enemigos a los que no se concede el status de ciudadano. Ciertamente esto es útil para la protección de bienes jurídicos, pero por esta protección tiene que ceder una parte de su esfera interna. Una disminución semejante del sujeto pertenece a un Derecho penal de índole peculiar que se diferencia nítidamente del Derecho penal de ciudadanos: el Derecho penal de enemigos optimiza la protección de bienes jurídicos, el Derecho penal de ciudadanos optimiza las esferas de libertad”. GÜNTHER JAKOBS. „Kriminalisierung im Vorfeld einer Rechtsgutsverletzung“ en: Zeitschrift für die gesamte Strafwissenschaft, vol. 97, 1985, p. 756. 
exista un ilícito material ${ }^{112}$, es necesario que el miembro tome participación activa en la asociación, o sea, es necesario que cada uno de los miembros realice un aporte a la asociación, entendiendo por tal la creación de un aparato delictivo organizado destinado a perdurar ${ }^{113}$.

Además del excesivo adelantamiento de la punición, la conspiracy presenta otras cuestiones problemáticas. En primer lugar, ante la inexistencia de un instrumento de análisis, como lo es la teoría del delito, el análisis dogmático en el sistema del Common Law se divide en una suerte de elementos objetivos (actus reus) y componentes subjetivos (mens rea). Sin embargo, esta división no funciona de manera plena para el delito aquí tratado, en el que el objeto del actus reus es justamente un acuerdo de componente subjetivo. A ello se le suma la poca precisión que proveen las diversas legislaciones en torno a los requisitos que debe tener el acuerdo para ser considerado válido. Esta falta de precisión aumenta la dificultad, cuando no acarrea la imposibilidad de plantear una defensa frente a un cargo por conspiración.

También el objeto del acuerdo es motivo de críticas. Si ya la asociación criminal es criticada por el hecho de que puede tener por objeto "delitos de cualquier tipo", cuanto más lo es la conspiracy que, en muchos casos, el objeto del acuerdo ni siquiera reúne los requisitos para ser considerado un ilícito, sino meros atentados contra la moral pública, que no son punibles cuando son realizados de manera individual; se convierten en punibles cuando son acordados por un grupo. Al tener un objeto tan amplio, la conspiracy puede ser el tipo penal utilizado tanto para imputar cargos relacionados con el crimen organizado, como para imputar meras infracciones a la moral pública.

También la doctrina Pinkerton resulta contraria a nuestro sistema de imputación jurídico-penal. El efecto de la doctrina es borrar la distinción entre autor y partícipe en operaciones criminales consensuadas. La prestación de ayuda (colaboración) en una conspiración existente, lo hace parte del grupo, pero no como partícipe (delito accesorio) sino como miembro pleno de la conspiración. La lógica es que la contribución equivale al acuerdo; un acuerdo implica una conspiración y esta implica responsabilidad como autor. Los delitos cometidos en cumplimiento de un acuerdo, hacen responsables a los demás conspiradores en calidad de autores. Acertadamente, Fletcher plantea que si la ley anglo-americana admitiera una más refinada clasificación entre autores y partícipes, el sistema debería abandonar la doctrina en cuestión, que efectivamente evita tratar al miembro de una conspiracy como partícipe, tratándolo

112 Se deduce que para que una conducta constituya la medida de un ilícito debe lesionar las condiciones para un desarrollo de la personalidad, en un pie de igualdad, de los hombres. Una conducta que no es perjudicial para las condiciones de desarrollo no es ningún ilícito material, cuando solo es valorada como inmoral por la sociedad. HeLMUT FRICHTER. Strafrecht: Allgemeiner Teil, $7^{\mathrm{a}}$ edición, München, C. H. Beck, 2015 , p. 35.

113 PATricia Ziffer. El delito de asociación ilícita, Buenos Aires, Ad-Hoc, 2005, p. 203. 
como autor ${ }^{114}$. Conforme a nuestro sistema de imputación, la mera pertenencia a una conspiración sería insuficiente para considerar al conspirador como coautor de los crímenes cometidos por otros conspiradores; para ello sería necesario que ambos realizaran conjuntamente el delito. El mero acuerdo de uno de los miembros para cometer el delito no es suficiente para constituir una comisión en conjunto. Tratar de extender la responsabilidad por los delitos cometidos en cumplimiento del acuerdo a todos aquellos que formaron parte de la conspiración no resulta factible, bajo ningún punto de vista, sin lesionar principios básicos del sistema de imputación, entre ellos, el de culpabilidad.

\section{LOS MODELOS DE "CONSPIRACY" Y "ASOCIACIÓN CRIMINAL" EN EL DERECHO INTERNACIONAL}

Son dos las Convenciones que imponen a los Estados partes la obligación de tipificar los delitos de conspiración y de asociación criminal. La Convención de Viena de 1988 estipula en su artículo 3.1 que

Cada una de las Partes adoptará las medias que sean necesarias para tipificar como delitos penales en su derecho interno, cuando se cometan intencionalmente: $(\ldots)$ c) a reserva de sus principios constitucionales y de los conceptos fundamentales de su ordenamiento jurídico: iv) la participación en la comisión de alguno de los delitos tipificados de conformidad con lo dispuesto en el presente artículo, la asociación y la confabulación para cometerlos...

Por su parte, el artículo 5.1 de la Convención de Palermo prescribe que

Cada Estado Parte adoptará las medidas legislativas y de otra índole que sean necesarias para tipificar como delito, cuando se cometan intencionalmente: a) Una de las conductas siguientes, o ambas, como delitos distintos de los que entrañen el intento o la consumación de la actividad delictiva: i) El acuerdo con una o más personas de cometer un delito grave con un propósito que guarde relación directa o indirecta con la obtención de un beneficio económico u otro beneficio de orden material y, cuando así lo prescriba el derecho interno, que entrañe un acto perpetrado por uno de los participantes para llevar adelante ese acuerdo o que entrañe la participación de un grupo delictivo organizado; ii) La conducta de toda persona que, a sabiendas de la finalidad y actividad delictiva general de un grupo delictivo organizado o de su intención de cometer los delitos en cuestión, participe activamente en: a. Actividades ilícitas del grupo delictivo organizado; b. Otras actividades del grupo delictivo organizado, a sabiendas de que su participación contribuirá

114 George P. Fletcher. Rethinking Criminal Law, New York, Oxford University Press, 2000, p. 660. 
al logro de la finalidad delictiva antes descrita; b) La organización, dirección, ayuda, incitación, facilitación o asesoramiento en aras de la comisión de un delito grave que entrañe la participación de un grupo delictivo organizado.

La primera de las Convenciones supedita la obligación de los Estados parte de tipificar la participación, la asociación o confabulación (conspiracy) en delitos relacionados con la producción y tráfico de estupefacientes y sustancias psicotrópicas en la medida que dichas categorías no contravengan principios constitucionales y conceptos fundamentales del ordenamiento jurídico interno. Esta salvedad se debe a las resistencias que genera el modelo de conspiracy en legislaciones no afines con el Common Law. Sin embargo, Argentina, siguiendo la normativa internacional, introdujo en la Ley de Estupefacientes la figura de la confabulación ${ }^{115}$, extendiendo la punibilidad a los meros acuerdos entre dos o más personas, en los delitos vinculados con narcotráfico. El delito de confabulación posee las características de la conspiracy, no exigiendo ni permanencia ni organización, como sí lo hace la figura asociación ilícita, reduciendo el tipo penal en cuestión a un mero delito de planeamiento. No existen razones político-criminales para fundar una punición tan adelantada y su aplicación produce una afectación del principio de lesividad (art. 19 Constitución Nacional) ${ }^{116}$. Además, intentar trasladar el funcionamiento de la conspiracy, con sus características de "delito autónomo" a nuestro sistema de imputación jurídicopenal, plantearía otras objeciones por la lesión del principio del ne bis in idem que generaría la aplicación concurrente de la confabulación y el delito fin para el que esta se conformó ${ }^{117}$.

El artículo 5 UNTOC, por su parte, ofrece dos enfoques alternativos a la criminalización de la participación en un grupo delictivo organizado, derivados de dos conceptos legales diferentes. La primera alternativa, es la participación en una conspiración tal como la define el art. 5.1(a) (i), que es propia de los países pertenecientes al sistema del Common Law. La segunda alternativa es la "participación en un grupo delictivo organizado" tal como es definida en el art. 5.1 (a)(ii), que es el delito de organiza-

115 Art. 29 bis de la ley 23.737, introducido por su modificatoria, ley 24.424: "Será reprimido con reclusión o prisión de 1 a 6 años, el que tomare parte en una confabulación de dos o más personas, para cometer algunos de los delitos previstos en los artículos $5^{\circ}, 6^{\circ}, 7^{\circ}, 8^{\circ}, 10$ y 25 de la presente ley, y en el artículo 866 del Código Aduanero.

"La confabulación será punible a partir del momento en que algunos de sus miembros realice actos manifiestamente reveladores de la decisión común de ejecutar el delito para el que se habían concertado.

"Quedará eximido de pena el que revelare la confabulación a la autoridad antes de haberse comenzado la ejecución del delito para el que se había formado, así como el que espontáneamente impidiera la realización del plan".

116 Art. 19: "Las acciones privadas de los hombres que de ningún modo al orden y a la moral pública, ni perjudiquen a un tercero, solo están reservadas a Dios, y exentas de la autoridad de los magistrados".

117 PATricia Ziffer. El delito de asociación ilícita, Buenos Aires, Ad-Hoc, 2005, pp. 304-305. 
ción típico de los países que siguen el sistema legal continental (Civil Law) ${ }^{118}$. De acuerdo con Vlassis ${ }^{119}$, el objetivo de esta combinación fue promover la cooperación internacional bajo la UNTOC, garantizando la compatibilidad de los dos conceptos sin intentar, hasta el momento, armonizarlos de manera completa ${ }^{120}$.

\section{La conspiracy en la UNTOC}

Según la Convención objeto de análisis, la participación en el delito de conspiración debe entrañar el acuerdo para cometer un delito grave, en los términos de la Convención, que tenga una relación directa con la obtención de un beneficio económico o material. De acuerdo con la UNTOC, "Por 'delito grave' se entenderá la conducta que constituya un delito punible con una privación de libertad máxima de al menos cuatro años o con una pena más grave" (art. 2 b unTOC). Así, el tradicional delito de conspiración es limitado en cuanto a los delitos que pueden ser objeto del acuerdo. Los conspiradores deben acordar no solo la persecución de un comportamiento definido por la Convención como delito grave: también deben acordar las previsibles consecuencias del acto, sin importar si esas consecuencias son causadas o no. El artículo en cuestión no establece ninguna especificación en torno a los requisitos que debe reunir el acuerdo para ser considerado una conspiración, lo que consideramos un gran déficit normativo, máxime teniendo en cuenta la poca claridad que reina en los sistemas que tipifican este delito en torno al elemento central del mismo. Ante la ausencia de mayores precisiones, el acuerdo podría ser concluido, incluso, de manera implícita.

Debido al hecho de que la esencia del delito de conspiracy es el "acuerdo de voluntades", que, por su naturaleza, es un suceso subjetivo, siempre ha sido muy difícil separar los elementos del delito entre objetivos (actus reus) y subjetivos (mens rea). La discusión en torno del elemento subjetivo se enfoca en el conocimiento y la intención de los conspiradores. Contrariamente a lo que sucede en los sistemas del Common Law, especialmente en Inglaterra y Gales, la interpretación del texto del

118 Matti Jousten. "International Cooperation against Transnational Organized Crime: Criminalising Participation in an Organized Criminal Group" en UNAFEI Annual Report for 2000 and Resource Material Series No. 59, Tokyo, unAFEI, 2002, p. 422. JoHn D. McCleAn. Transnational Organized Crime: a Commentary on UN Convention and its Protocols, Oxford, Oxford University Press, 2007, p. 62 .

119 Dimitri Vlassis. “The United Nations Convention Against Transnational Organized Crime and its Protocols: A New Era in International Cooperation" en The Changing Face of International Criminal Law: Selected Papers, Vancouver, The International Centre for Criminal Law Reform and Criminal Justice Policy, 2002, p. 92.

120 Almir Maljevic. "Participation in a Criminal Organization” and "Conspiracy". Different Legal Model Against Criminal Collectives, Duncker \& Humblot, Berlin, 2011, pp. 139-140. 
artículo objeto de análisis conduce a la conclusión de que los conspiradores tienen que saber que lo que han acordado constituye un delito ${ }^{121}$.

Dos elementos adicionales alternativos, diseñados para contribuir a la objetivación de la conspiración, son mencionados específicamente, a condición de que un requisito comparable exista en la ley interna. El primero es el relacionado con el acto perpetrado en cumplimiento del acuerdo conspiracional (overt act). Siguiendo las previsiones del Derecho interno referidas al acto manifiesto y en ausencia de mayores especificaciones por la normativa internacional, del análisis de la norma en cuestión se concluye que el acto realizado por uno de los conspiradores no necesita ser ilícito. El elemento en cuestión debería ser interpretado como no necesitado de nada más que de un acto por el cual uno de los conspiradores está actuando en cumplimiento del acuerdo. Por otra parte, con la condición de la existencia del elemento en el Derecho interno, deja a resguardo a aquellas jurisdicciones, como es el caso de Inglaterra y Gales, en las cuales la conspiración es un concepto más laxo, que queda consumada con el mero acuerdo.

El segundo elemento adicional es que la conspiración entrañe la participación en un "grupo delictivo organizado". Este elemento adicional limitativo de la conspiración debería estar prescripto por la ley interna. De existir el mismo, individuos que acuerdan cometer un delito considerado grave conforme a la Convención, no pueden ser acusados de conspiración a menos que cumplimenten los requisitos para ser calificados como un grupo delictivo organizado (art. 2 a UNTOC $)^{122}$. En la práctica, este requisito no tiene aplicación, pues los diversos sistemas siguen operando con la categoría conspiracy, en el caso del Common Law o asociación criminal en el caso del sistema continental, considerando que los respectivos conceptos satisfacen las exigencias del artículo 2 a UNTOC. El concepto de grupo delictivo organizado acuñado en Palermo no ha tenido receptación, salvo excepciones ${ }^{123}$, en las legislaciones internas, pues ellas siguen utilizando, a tal fin, los tipos penales de conspiracy y de asociación criminal, respectivamente, preexistentes al concepto acuñado por la $\mathrm{UNTOC}^{124}$.

121 Maljevic considera que los conspiradores no deben, necesariamente, saber que ese delito es considerado grave. Esta conclusión la extrae del hecho de que la UNTOC no exige a los Estados que definan lo que constituye un "delito grave" en sus respectivas legislaciones. Almir MALJEvic. "Participation in a Criminal Organization” and "Conspiracy”. Different Legal Model Against Criminal Collectives, Duncker \& Humblot, Berlin, 2011, p. 144.

122 A los fines de saber qué se entiende por "grupo criminal organizado" véase punto siguiente.

123 En la práctica, el Código Penal español mantiene tres vías de punición para las organizaciones criminales, a saber: 1) a través de los subtipos agravados cuando el delito se hubiese cometido a través de una organización criminal; 2) mediante la punición de la asociación ilícita (art 515) y 3) a través del tipo de organización criminal (art. 750 bis y ss.). A esta última la define del siguiente modo: "A los efectos de este Código se entiende por organización criminal la agrupación formada por más de dos personas con carácter estable o por tiempo indefinido, que de manera concertada y coordinada se repartan diversas tareas o funciones con el fin de cometer delitos" (art. 750 bis CP).

124 Véase nota al pie número 31. 


\section{Participación en un grupo delictivo organizado}

El delito definido por el art 5.1 (a) (ii) UNTOC exige la criminalización de la participación en una forma específica de asociación criminal, a saber, en un "grupo delictivo organizado". Con el fin de evitar diversas interpretaciones del término, la UNTOC provee de un concepto de "grupo delictivo organizado" en su art 2. "Para los fines de la presente Convención: a) Por 'grupo delictivo organizado' se entenderá un grupo estructurado de tres o más personas que exista durante cierto tiempo y que actúe concertadamente con el propósito de cometer uno o más delitos graves o delitos tipificados con arreglo a la presente Convención con miras a obtener, directa o indirectamente, un beneficio económico u otro beneficio de orden material". El concepto en cuestión consta de diversos elementos en torno al número mínimo de personas, duración, forma de actuación del grupo y clases de delitos fin. A continuación, haremos un análisis de los mismos.

El único elemento que no exige demasiadas explicaciones es el relativo al número de mínimos de personas involucradas. La Convención, al igual que el delito de asociación criminal en el derecho interno, exige un mínimo de tres personas. Ello es así dado que un número inferior no podría satisfacer las demás exigencias del tipo. En la práctica resulta harto dudoso que un grupo delictivo organizado de solamente tres personas pueda satisfacer las exigencias de organización y actuar concertado ${ }^{125}$.

El grupo delictivo organizado debe estar compuesto por "un grupo estructurado", concepto que también está establecido en la UNTOC. El artículo 2 c) reza: "Por 'grupo estructurado' se entenderá un grupo no formado fortuitamente para la comisión inmediata de un delito y en el que no necesariamente se haya asignado a sus miembros funciones formalmente definidas ni haya continuidad en la condición de miembro o exista una estructura desarrollada". A través de este concepto se ha querido trazar la división con el actuar concertado de varias en un delito específico (participación) ${ }^{126}$, exigiendo que el grupo delictivo organizado no se limite a un solo ilícito. A la vez que establece precisiones -bastantes laxa, por cierto- en torno a la organización interna del grupo. La definición de UNTOC de "grupo estructurado" debería, por lo tanto, ser entendida como prescribiendo un mínimo nivel de asociación requerido

125 Valen aquí las apreciaciones de Rudolphi respecto de la asociación criminal, al considerar que, salvo raras excepciones, un grupo de tres o cuatro personas pueda desplegar una dinámica propia que promueva y favorezca, de una manera especial, la comisión de los delitos planeados a través de sus miembros. HANS-JOACHIM RUdOLPHI (1978), ,Verteidigerhandeln als Unterstützung einer kriminellen oder terroristischen Vereinigung i. S. der §§ 129 a StGB“ en Festschrift für H.J. Brums zum 70. Geburtstag, Köln, Heymann, p. 320.

126 En palabras de Silva Sánchez: "En esa dimensión institucional radica, seguramente, su diferencia específica con respecto a las meras agrupaciones coyunturales para cometer delitos”. JESÚs-MARÍA SILVA SÁNCHEZ. "La 'intervención a través de organización’ ¿una forma moderna de participación en el delito?” en Manuel Cancio Melía, Jesús-María Silva Sánchez, Delitos de organización, Buenos Aires, B de F, 2008, p. 95. 
para que el colectivo pueda ser considerado un grupo delictivo organizado y excluyendo a aquellos colectivos que no encuentran dicho estándar, así como también descartando la mera complicidad (participación). El término "grupo estructurado" debe ser usado en sentido amplio, para incluir a grupos con estructura jerárquica u otra elaborada y a grupos no jerárquicos donde los roles de los miembros del grupo no necesitan estar formalmente definidos.

Un requisito que requiere mayores precisiones es el relativo a la duración que debe tener el grupo. La UNTOC se limita a establecer "que exista durante cierto tiempo". Interpretando dicha previsión de manera sistemática con el artículo 2 c, según el cual el grupo no debe tener carácter aleatorio para la comisión inmediata de un delito, el tiempo necesario para la preparación y ejecución de un solo delito resultaría insuficiente para satisfacer el límite temporal. Por otro lado, el grupo delictivo organizado puede tener como finalidad la comisión de un delito grave. Las definiciones a y c del artículo 2 resultan, en cierto modo, contradictorias. A fin de intentar superar las contradicciones existentes, consideramos que, a los fines de determinar el tiempo mínimo de duración exigido para la existencia de un grupo delictivo organizado, es necesario, como mínimo, un lapso para organizar y ejecutar operaciones delictivas complejas, incluyendo, como mínimo un "delito grave". Esto es así dado que, a diferencia de nuestro Derecho interno donde la asociación criminal debe tener como finalidad la comisión de múltiples delitos (en un número indeterminado), la UNTOC posibilita que el grupo delictivo organizado tenga por objeto un único delito grave.

El grupo delictivo organizado exige además un "actuar concertado" de sus miembros, lo que no debe ser interpretado en el sentido de actuar simultáneo. Actuar concertado significa que los miembros del grupo actúan conforme a un plan y contribuyen, de una u otra forma, a la finalidad común del grupo, complementándose entre ellos, de modo tal que las acciones representan el resultado alcanzado de manera conjunta.

La UNTOC también especifica los fines del grupo delictivo organizado. Conforme a la definición objeto de análisis, el fin directo del grupo debe ser cometer delitos graves o delitos establecidos de acuerdo a la Convención y sus Protocolos (blanqueo del producto del delito, corrupción, trata de personas, tráfico ilícito de migrantes, fabricación y tráfico ilícito de armas de fuego, sus piezas y componentes y municiones). Además, esta finalidad debe ser llevada a cabo por el propósito de obtener, directa o indirectamente, beneficio económico u otro beneficio material. Grupos cuyas finalidades sean solo políticas, religiosas, etc., están excluidos del ámbito de aplicación de la UNTOC.

\section{Formas de participación}

La participación en un grupo delictivo organizado consiste en la conducta de una persona que, con conocimiento, ya sea de la finalidad y de la actividad criminal general de un grupo delictivo organizado o de su intención de cometer los delitos en 
cuestión, toma parte activa ya sea en las actividades criminales del grupo delictivo organizado, o en otras actividades del grupo delictivo organizado con conocimiento de que su participación contribuirá al logro de la finalidad criminal. Existen dos formas posibles de participación en un grupo delictivo organizado. La primera, es participación en actividades criminales del grupo delictivo organizado con conocimiento ya sea de la actividad criminal general del grupo o de su intención de cometer delitos. La segunda modalidad es la participación en actividades no criminales del grupo delictivo organizado con el conocimiento de que las propias actividades contribuirán al logro de la finalidad criminal del grupo delictivo organizado ${ }^{127}$. La distinción entre estas formas de participación es solamente a los fines teóricos, pues la UNTOC no señala que deban aplicárseles escalas penales diferenciadas.

\section{Otras formas de participación}

Con el objetivo de capturar toda forma posible de conducta de colaboración en un grupo delictivo organizado, el artículo 5 b) de la UNTOC exige a los Estados parte criminalizar las actividades de organización, dirección, ayuda, incitación, facilitación o asesoramiento con la finalidad de cometer un delito en la medida que conlleve la participación de un grupo delictivo organizado. Con esta previsión, la UNTOC intenta criminalizar formas de participación en las actividades de un grupo delictivo organizado que van más allá de la mera dirección, pues solo las primeras dos formas de participación definidas por esta previsión, a saber, organizar y dirigir, tienen como finalidad criminalizar las acciones de los individuos que dan órdenes o que de otra manera ejercen el control sobre los miembros de la organización o sobre sus actividades, mientras que las restantes formas están dirigidas a criminalizar meras complicidades. Ayudar, instigar, facilitar y aconsejar, a pesar de estar mencionadas en la UNTOC como formas distintivas de participación, resultan redundantes. Todas las formas de participación no representan otra cosa que contribución a la comisión de un delito cometido por otro. Dicho de otro modo, individuos que ejecutan actividades que son calificadas como ayudar, instigar y facilitar o aconsejar son partícipes en sentido estricto (instigadores o cómplices). Siguiendo el principio de accesoriedad, todas las formas de participación presuponen que el autor principal ha comenzado ya a cometer el delito. El apartado b) resulta redundante, no es más que una aclaración, especificando los modos de participación del apartado 5.1 a (ii).

127 Un ejemplo de tal actividad sería el abastecimiento intencional de medios financieros al grupo organizado con el propósito de que se alcance la finalidad del grupo, pero sin conocimiento detallado sobre los delitos a ser cometidos, y sin ningún ulterior involucramiento en ningún tipo de actividad criminal del grupo. 


\section{CONCLUSIONES}

La dogmática jurídico-penal alemana atraviesa un periodo de crisis marcado por la pérdida de relevancia internacional; si bien mantiene un número de Estados fieles seguidores de su tradición jurídica, no ha logrado ser un actor central en el desarrollo de la normativa penal internacional. De un tiempo a esta parte, las nuevas manifestaciones delictivas (piénsese en los delitos relacionados con el tráfico de estupefacientes, la trata de personas, el lavado de activos, etc.) han tenido su origen en un sistema de imputación jurídico-penal diverso, al utilizado por nosotros. La política criminal de los EE.UU. tiene alcance global, a partir de su posición dominante en las Convenciones internacionales en la materia. El hecho de que los nuevos tipos penales sean elaborados en función de otro sistema de imputación trae como consecuencia, entre otras cosas, la disfuncionalidad de los mismos a la hora de ser aplicados en función del Derecho interno. Entre otras particularidades, los mismos implican un excesivo adelantamiento de la punición alcanzando las etapas preparatorias o, dada la redacción de los tipos, que cuentan con múltiples acciones típicas, quedan capturados bajo el concepto de autor acciones que deberían ser consideradas de colaboración en el hecho principal, diluyendo de este modo la distinción entre autor y partícipe.

En el último tiempo, los delitos de organización han experimentado una expansión en los Derechos internos, especialmente a partir de la aparición de subtipos calificados en los que se agrava la conducta básica cuando el mismo sea cometido a través de una "asociación" o en "banda".

La conspiracy y la participación en una asociación criminal son tratadas, a veces, como tipos penales equivalentes, pertenecientes a diversos sistemas jurídicos ${ }^{128}$. Si bien ambos modelos están basados en fundamentos preventivos similares, fundados en el adelantamiento de la punición y en la mayor peligrosidad que representa el grupo frente al autor individual, difieren en el ámbito de aplicación. La conspiracy tiene un ámbito de aplicación mucho más basto que la asociación criminal. La amplitud de la conspiracy no solo está basada en la falta de precisión del elemento central del tipo, el acuerdo, ni en los múltiples hechos que pueden ser objeto de conspiración, desde meras alteraciones a la moral pública hasta su aplicación a casos de crimen organizado. El problema principal de la conspiracy radica en el excesivo adelantamiento de la punición, llegando a etapas que deberían estar fuera del alcance del poder punitivo. Un mero acuerdo delictivo entre dos o más personas, que se perfecciona con el encuentro de voluntades y que, contrariamente a lo que sucede con la asociación criminal, no se exige ni permanencia ni organización, termina siendo un mero delito de planeamiento, resultando excesivo habilitar el poder punitivo a etapas tan tempranas,

128 Especialmente en la cooperación internacional a la hora de proceder a otorgar una extradición. 
afectando de ese modo el ámbito de privacidad de los particulares ${ }^{129}$. Por otro lado, la aplicación de la conspiracy, tal como funciona en los sistemas del Common Law, puede acarrear una violación del principio de prohibición de doble valoración (ne bis in idem), especialmente si se lo considera como delito autónomo que concurre, de manera material, con el delito fin de la conspiración. Dados los problemas que acarrea la aplicación del modelo de conspiracy en nuestro sistema, cual elefante en un bazar, esta no puede ser aplicada sin afectar principios penales básicos.

En los modelos internaciones, si bien mantienen las diferencias entre conspiracy y asociación criminal, aunque existen transiciones entre los modelos. En especial, la UNTOC permite a los Estados complementar los requisitos básicos, principalmente los elementos subjetivos de la conspiracy con algunos elementos objetivos, como la necesidad de que el mismo sea llevado a cabo por un grupo delictivo organizado que la acercan al modelo opuesto.

Por otro lado, el concepto de "grupo delictivo organizado" tiene sus diferencias con los conceptos prexistentes de asociación criminal o asociación ilícita. No obstante, la intención de la UNTOC de aportar un concepto unificador del fenómeno de la criminalidad organizada, los diversos Estados parte siguen operando con conceptos preexistentes en sus legislaciones. Hasta la fecha, no existe ni en el Derecho interno, ni a nivel del Lebenswelt ${ }^{130}$, un concepto común.

129 Como bien aclara Zaffaroni: "cualquiera sea la lesión a la que quiere anticiparse la programación criminalizante, ésta no puede extenderse -en la tentativa ni en el delito de peligro- más allá del ámbito circunscripto por el peligro de lesión, sino en violación del art. 19 constitucional que consagra el principio de libertad negativa o de reserva. Por esta razón quedan excluidos los cursos de acción que solo revelan una posibilidad de afectación abstracta, en los que no se hace más que usar un discurso pretendidamente tutelar de bienes jurídicos para habilitar el ejercicio del poder punitivo en razón de meras desobediencias administrativas o de criterios de moral subjetiva". EUGENIO RAÚl ZAFFARONI et al. Derecho penal: parte general, $2^{a}$ edición, Buenos Aires, Ediar, 2002, pp. 809-810.

130 Seguimos el concepto de Lebenswelt adoptado por Alfred Schütz, quien considera al mundo de la vida cotidiana "ingenua y pre-reflexivamente dado", no como algo "puesto entre paréntesis" sino, por el contrario, como el campo que el científico social no puede nunca abandonar, como el "hábitat natural" del problema del Verstehen. El mundo de la vida cotidiana incluye todo aquello que es dado por sabido y que normalmente no requiere reflexión, es una actitud de sentido común. ZYGMUNT Bauman. La hermenéutica y las ciencias sociales, Buenos Aires, Nueva visión, 2007, p. 168. Para Schütz: "Todas las explicaciones científicas del mundo social pueden, y para ciertos fines, deben referirse al sentido subjetivo de las acciones de seres humanos en los que se origina la realidad social" ALFRED SCHÜTZ. El problema de la realidad social: Escritos I, Buenos Aires, Amorrortu, 1974, p. 63. El Lebenswelt se constituye de este modo en el escenario y el objeto de nuestras acciones e interpretaciones. Alfred SchÜTZ. On Phenomenology and Social Relations, Chicago, Chicago University Press, 1973, p. 73. El mundo de la vida cotidiana es también, desde el principio, un mundo social cultural dentro del cual las personas se relacionan, en múltiples formas de interacción, con semejantes a quienes conocen en grados diversos de intimidad y anonimia. Y solo en él se puede constituir un entorno comunicativo común (gemeinsame kommunikative Umwelt). AlfRED ScHÜTZ, Thomas Luckmann, Strukturen der Lebenswelt. Konstanz, C.H. Beck, 2003, p. 29. 
Consideramos que el modelo de conspiracy es incompatible con los principios de responsabilidad criminal tal como son definidos por nuestro sistema de imputación jurídico-penal, de acuerdo con el cual las personas son consideradas responsables por sus propios hechos más que por lo que ellas piensan o acuerdan sobre ello. Como es de esperar, algunos Estados que siguen la tradición legal del sistema continental nunca sumarán el concepto de conspiracy a sus legislaciones domésticas. Sin embargo, la tendencia opuesta no puede ser descartada y las legislaciones internas ${ }^{131}$, con el fin de considerar criminales conductas que, de una u otra forma, pueden no estar cubiertas por las previsiones sobre participación en asociaciones criminales, introduzcan tipos penales con características similares a la conspiracy.

\section{BIBLIOGRAFÍA}

Aмвоs, KaI. "Zur Zukunft der deutschen Strafrechtswissenschaft: Offenheit und diskursive Methodik statt selbstbewusster Provinzialität“", en: Tiedemman, KLAUs et al. (eds.) Die Verfassung moderner Strafrechtspflege. Erinnerung an Joachim Vogel, Nomos, Baden-Baden, pp. 321-347, 2016.

Амвоs, KaI. Internationales Strafrecht. Strafanwendungsrecht-Völlkerstrafrecht - Europäisches Strafrecht - Rechthilfe, 4. Auflage, München: C. H. Beck, 2014pp. 100-101.

Amenge Oкотн, Juliet R. The Crime of Conspiracy in International Criminal Law, Heidelberg, Springer, 2014.

Bauman, Zygmunt. La hermenéutica y las ciencias sociales, Buenos Aires, Nueva visión, 2007.

BoISTER, NeIL. “Transnational International Law?", in: European Journal of International Law, vol. 14, 2003, pp. 953-976.

Boumpadre, Jorge. Derecho penal: parte especial, T. II, Mario A. Viera Editor, Buenos Aires, 2001.

Brownlie, Ian. Principles of Public International Law, 6 a edición, Oxford, Oxford University Press, 2003.

131 En el caso de Argentina, el artículo 29 bis de la Ley de Estupefacientes (Ley n 23.737), antes mencionado. El Código Penal del Reino de España, por su parte, en su artículo 519 tipifica la conspiración para cometer asociación ilícita en los siguientes términos "La provocación, la conspiración y la proposición para cometer el delito de asociación ilícita se castigarán con la pena inferior en uno o dos grados a la que corresponda, respectivamente, a los hechos previstos en los artículos anteriores". 
VON BubnOFF, EcKHART. “\$ 129” en BuRKhARd JÄNKE, et al (eds.) Strafgesetzbuch. Leipziger Kommentar, $11^{\mathrm{a}}$ edición, Berlin, Walter de Gruyter, Tomo 4, 2005.

Cancio Meliá, Manuel. "El injusto en los delitos de organización": peligro y significado" en Manuel Cancio Melía, Jesús-María Silva Sánchez, Delitos de organización, Buenos Aires, B de F., 2008.

CAssese, Antonio. International Criminal Law, $2^{\text {nd }}$ ed., Oxford: Oxford University Press, 2007.

Clarkson, C. M.V.; Keating, H. M.; Cunningham, S. R. (). Clarkson and Keating Criminal Law: Text and Materials, $6^{\mathrm{a}}$ edición, London, Sweet \& Maxwell, 2007.

D’Alessio, José Andrés (director). Código Penal: comentado y anotado: parte especial (arts. 79 a 306), Buenos Aires, La Ley, 2004.

De Sousa Santos, BoAventura. Crítica de la razón indolente: contra el desperdicio de la experiencia: para un nuevo sentido común: la ciencia, el derecho y la política en la transición paradigmática, Bilbao, Desclée de Brouwer, 2003.

Donna, Edgardo. Derecho penal: parte especial. Buenos Aires, Rubilzal Culzoni, Tomo II-C, 2002.

Fletcher, GeORge P. Gramática del Derecho penal, traducción castellana de FrANCisco Muñoz Conde, Buenos Aires, Hammurabi, 2008.

Fletcher, George P. Rethinking Criminal Law, New York, Oxford University Press, 2000.

Frichter, Helmut. Strafrecht: Allgemeiner Teil, $7^{\text {a }}$ edición, München, C. H. Beck, 2015.

HARrison, DAVID. Conspiracy as a Crime and as a Tort in English Law, London, Sweet \& Maxwell, 1924.

Harvard Law Review Association. "The Conspiracy Dilemma: Prosecution of Group Crime or Protection of Individual Defendants" en Harvard Law Review, Vol. 62, n. ${ }^{\circ}$ 2, 1948, pp. 276-286.

HASSEMER, WiLfRIED. "Person, Welt und Verantwortlichkeit Prolegomena einer Lehre von der Zurechnung im Strafrecht” en KLAUs LÜDERSSEN (comp.), Aufgeklärte Kriminalpolitik oder Kampf gegen das Böse?, Nomos: Baden-Baden, Tomo I, 1998, pp. 350-372. 
Hazell, Robert. Conspiracy and civil liberties: a memorandum submitted to the Law commission by the Cobden Trust and the National Council for Civil Liberties, London, Bell, 1974.

HruschKa, JoAchim. Strukturen der Zurechnung, Berlin, Walter de Gruyter, 1976.

JAKOBS, GÜNTHER. „Kriminalisierung im Vorfeld einer Rechtsgutsverletzung“ en Zeitschrift für die gesamte Strafwissenschaft, 1985, vol. 97, 1985, pp. 751-785.

JefFerson, Michael. Criminal Law, $11^{\text {a }}$ edición, London, Pearson.

JesCHECK, JANS-HeInRICH, WeIGEND ThOMAs. Lehrbuch des Strafrechts. Allgemeiner Teil, $5^{\text {a }}$ edición, Duncker \& Humblot, Berlin, 2013.

Johnson, PhiLip. "The Unnecessary Crime of Conspiracy" en Californian Law Review, vol. 61, issue 5, 1973, pp. 1.137-1.188.

Jousten, MATTI. “International Cooperation against Transnational Organized Crime: Criminalising Participation in an Organized Criminal Group" en UNAFEI Annual Report for 2000 and Resource Material Series No. 59, Tokyo, UNAFEI, 2002, pp. 417-428.

KAUFMANN, ARMIN. "Das Übernationale und Überpositive in der Strafrechtswissenschaft", en HANS-HEINRICH JESCHECK, et al (eds). Gedächtnisschrift für Zong Uk Tjong, Seibundo, Tokio, 1985, pp. 100-111.

KIndHÄUsER, URs. Strafrecht: Allgemeiner Teil, $4^{\mathrm{a}}$ edición, Nomos, Baden-Baden. 2009.

KINDHÄUSER, URS. Gefährdung als Straftat: rechtstheoretische Untersuchungen zur Dogmatik der abstrakten und konkreten Gefährdungsdelikte, Frankfurt am Main, Klostermann, 1989.

Kohlrausch, Eduard, LANGe, Richard. Strafgesetzbuch mit Erläuterungen und Nebengesetzen, 43 ${ }^{\mathrm{a}}$ edición Berlin, Walter de Gruyter, 1961.

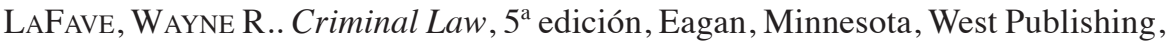
2010 .

VON LAMPE, Klaus. Organized Crime: Analyzing Illegal Activities, Criminal Structures, and Extra-Legal Governance, Los Angeles, Sage, 2016.

VON LAMPE, KLAUS. "The study of organised crime: An assessment of the state of affairs" en Organised Crime: Norms, markets, regulation and research, Oslo, Unipub, 2009, pp. 165-211. 
vON LAMPE, KlaUs. “Organised Crime Research in Perspective” en: Upperworld and Underworld in Cross-Border Crime, Nijmegen: Wolrd Legal Publishers, 2002, pp. 189-198.

LANGER-STEIN, RoSE. Legitimation und Interpretation der strafrechtlichen Verbote krimineller und terroristischer Vereinigungen (§§ 129, 129a StGB), München, Florentz, 1987.

Maljevic, Almir. "Participation in a Criminal Organization" and "Conspiracy". Different Legal Model Against Criminal Collectives, Duncker \& Humblot, Berlin. 2011.

MAURACH, ReINHART. Strafrecht: Besonderer Teil, $5^{\mathrm{a}}$ edición, Karlsruhe, C. F. Müller, 1969 .

MCClean, John D. Transnational Organized Crime: a Commentary on un Convention and its Protocols, Oxford, Oxford University Press, 2007

Miebach, Klaus, SchäFer, JÜrgen. “§ 129” en Klaus Miebach (ed.) Münchener Kommentar zum Strafgesetzbuch, $3^{\text {a }}$ edición, München, C. H. Beck, Tomo 3. 2017

Nadelmann, Ethan. Cops Across Borders: The Internationalization of U.S. Criminal Law Enforcement, Pennsylvania, State University Press. 1993

Núñez, Ricardo. Tratado de Derecho Penal, Córdoba, Marcos Lerner Editora, Córdoba, tomo v, vol. I, 1992.

ОвокатА, Том. Transnational Organised Crime in International Law, Oxford, Hart Publishing, 2010.

ОвокатА, Том. "Trafficking of Human Beings as a Crime against Humanity: Some Implications for the International Legal System" en International and Comparative Law Quarterly, vol. 54, 2005, pp. 445-457.

PERron, WALTER. "Europäische und transnationale Strafrechtspflege als Herausforderung für eine moderne Strafrechtdogmatik“, en KLAus TiEdEMman, et al (eds.) Die Verfassung moderner Strafrechtspflege. Erinnerung an Joachim Vogel, Nomos, Baden-Baden, 2016, pp. 307-317.

Robertson, Geoffrey. Whose Conspiracy?, London, National Council for Civil Liberties, 1974. 
Romero SÁnchez, Angélica. La Asociación criminal y los delitos en banda en el Derecho penal alemán: Fundamentos históricos, dogmáticos y de política criminal, Bogotá, Universidad Externado de Colombia, 2015.

Rosa, HaRtmut. Beschleunigung. Die Veränderung der Zeitstruktur in der Moderne, Frankfurt am Main, Suhrkamp, 2005.

Roxin, Claus. "Die Strafrechtswissenschaft von den Angaben der Zukunft" en AlBIN ESSER et al. (eds). Die deutsche Strafrechtswissenschaft vor der Jahrtausendwende. Rückbesinnung und Ausblick, München, Beck, 2000, pp. 369-395.

Roxin, Claus. “\$ 30” en Burkhard Jänke et al. (eds.) Strafgesetzbuch. Leipziger Kommentar, 11 a edición, Berlin, Walter de Gruyter, Tomo 1, 2005.

Rubio, Zulma Lidia. El delito de asociación ilícita, Buenos Aires, Librería Editora Platense, 1981.

RudOLPHI, HANS-JOACHIM. „Notwendigkeit und Grenzen einer Vorverlagerung des Strafrechtsschutzes im Kampf gegen den Terrorismus“ en Zeitschrift für Rechtspolitik, Cuaderno 9, 1979, pp. 214-221.

RudOLPHI, HANS-JOACHIM. ,Verteidigerhandeln als Unterstützung einer kriminellen oder terroristischen Vereinigung i. S. der $\S \S 129$ a StGB“" en Festschrift für H.J. Brums zum 70. Geburtstag, Köln, Heymann, 1978, pp. 315-338.

Rudolphi, Hans-Joachim; Stein, Ulrich. „\$129“ en Jürgen Wolter (ed.) Systematischer Kommentar zum Strafgesetzbuch, $8^{\text {a }}$ edición, Köln, Carl Heymanns, Tomo 3, 2012.

Soler, Sebastián. Derecho Penal argentino, Buenos Aires, Tipográfica Editora Argentina, Tomo 4, 1992.

SCHÜTZ, AlfRED. El problema de la realidad social: Escritos I, Buenos Aires, Amorrortu, 1974.

SchÜtz, Alfred. On Phenomenology and Social Relations, Chicago, Chicago University Press, 1973.

Schütz, Alfred; Luckmann, Thomas. Strukturen der Lebenswelt, Konstanz, C.H. Beck, 2003.

Stazger, Helmut. "Die Rolle einer modernen deutschen Strafrechtswissenschaft im europäischen und internationalen Kontext", en KLAus TiEdEMman et al. (eds.) 
Die Verfassung moderner Strafrechtspflege. Erinnerung an Joachim Vogel, Nomos, Baden-Baden, 2016, pp. 277-283.

Shabas, William. "International Crime", en David Amstrong (ed.) Routledge Handbook of International Law, London, Routledge-Cavendish, 2008, pp. 268-280.

SiEBer, UlRich. "Strafrechtsvergleichung im Wandel - Aufgaben, Methoden und Theorieansätze der vergleichenden Strafrechtswissenschaft -“"en UlRICH SIEBER, HANS-JÖRG AlbRECHT (eds.). Strafrecht und Kriminologie unter einem Dach, Kolloquium zum 90. Geburtstag von Professor Dr. Dr. h.c. mult. Hans-Heinrich Jescheck am 10. Januar 2005, Duncker \& Humblot, Berlin, 2006, pp. 78-151.

Silva SÁnCheZ, Jesús-MARÍA. "Prólogo 2012. El sistema moderno del derecho penal: cuestiones fundamentales", en BERD SCHINEMANN (comp.) El sistema moderno del derecho penal. Cuestiones fundamentales. Estudios en honor del Claus Roxin en su $50^{\circ}$ aniversario, $2^{\mathrm{a}}$ edición, Buenos Aires, B de F, 2012, pp. XV-XVI.

Silva SÁnChEZ, Jesús-MARÍA. “La ‘intervención a través de organización’ ¿una forma moderna de participación en el delito?" en Manuel Cancio Melía, Jesús-María Silva SÁnchez, Delitos de organización, Buenos Aires, B de F, 2008, pp. 87-118.

Silva SÁnchez, Jesús-María. La expansión del derecho penal. Aspectos de la política criminal en sociedades postindustriales, $2^{\text {a }}$ edición, Madrid, Civitas.

Sinn, ARnDT. Organisierte Kriminalität 3.0, Heidelberg, Springer, 2001.

TRIFFTERER, ОтTO. Dogmatische Untersuchungen zur Entwicklung des materiellen Völkerstrafrechts seit Nürnberg, Freiburg i. Br., Albert, 1966.

Vaurs Chaumette, Anne-Laure. Les sujets du droit international pénal. Vers une nouvelle définition de la personnalité juridique internationale?, Paris, Pedone, 2009.

Vlassis, DiMITRI. "The United Nations Convention Against Transnational Organized Crime and its Protocols: A New Era in International Cooperation" en The Changing Face of International Criminal Law: Selected Papers, Vancouver, The International Centre for Criminal Law Reform and Criminal Justice Policy, 2002, pp. 75-103.

VOGEL, JOACHIM. "Strafrecht und Strafwissenschaft im internationales und europäisches Rechtsraum“, en Juristen Zeitung, 2012, pp. 25-31.

Vogel, JoACHIM. "La internacionalización del Derecho penal y del Proceso penal", en: Revista penal, vol. 22, 2008, pp. 160-167. 
VoGEL, JOACHIM. "Europäische Kriminalpolitik - europäische Strafrechtsdogmatik" en: Goltdammer's Archiv für Strafrecht, 2002, pp. 517-534.

Welzel, Hans. Vom Bleibenden und vom Vergänglichen in der Strafrechtswissenschaft, Marburg a. d. Lahn, Elwert, 1964.

WoOdiwiss, Mike. "Transnational organised crime: the global reach of an American concept”. A. Edwards, P. Gill (eds.), Transnational Organised Crime. Perspectives on global security. London, Routledge, 2003, pp. 13-28.

Zaffaroni, Eugenio Raúl et al. Derecho penal: parte general, $2^{\mathrm{a}}$ edición, Buenos Aires, Ediar, 2002.

Ziffer, PATricia. El delito de Asociación ilícita, Buenos Aires, Ad-Hoc. 2005.

Referencias jurisprudenciales

Jurisprudencia de la Corte Suprema de Justicia

de los Estados Unidos de América

Pinkerton vs United States, 328 U.S. 640 (1946)

Yates vs United States, 355 U.S. 66 (1957)

Jurisprudencia del Bundesgerichtshof (BGH)

(Tribunal de Justicia Federal de Alemania)

BGH v. 12.10.1965, NJW 1966.

BGH V. 12.02.1975, NJW 1975.

BGH v. 21.12.1977, NJW 1978.

BGH v. 11.10.1978, NJW 1979.

BGH v. 03.10.1979, NJW 1980.

BGH v. 05.01.1982, NJW 1982.

BGH v. 13.01.1983, NJW 1983.

BGH v. 02.02.1983, NJW 1983.

BGH v. 25.07.1984, NJW 1984.

BGH v. 22.02.1995, NJW 1995.

BGH v. 21.10.2004, NJW 2005.

BGH v. 10.03.2005, NJW 2005.

BGH v. 10.01.2006, NJW 2006. 